Hydrology and Earth System Sciences, 6(2), 167-183 (2002) C $\quad$ EGS

\title{
Heterogeneity in catchment properties: a case study of Grey and Buller catchments, New Zealand
}

\author{
Ude Shankar, Charles P. Pearson, Vladimir I. Nikora and Richard P. Ibbitt \\ National Institute of Water and Atmospheric Research, P.O. Box 8602, Christchurch, New Zealand
}

Email for corresponding author: u.shankar@niwa.cri.nz

\begin{abstract}
The scaling behaviour of landscape properties, including both morphological and landscape patchiness, is examined using monofractal and multifractal analysis. The study is confined to two neighbouring meso-scale catchments on the west coast of the South Island of New Zealand. The catchments offer a diverse but largely undisturbed landscape with population and development impacts being extremely low. Bulk landscape properties of the catchments (and their sub-basins) are examined and show that scaling of stream networks follow Hack's empirical rule, with exponents $\sim 0.6$. It is also found that the longitudinal and transverse scaling exponents of stream networks equate to $v_{l} \approx 0.6$ and $v_{w} \approx 0.4$, indicative of self-affine scaling. Catchment shapes also show self-affine behaviour. Further, scaling of landscape patches show multifractal behaviour and the analysis of these variables yields the characteristic parabolic curves known as multifractal spectra. A novel analytical approach is adopted by using catchments as hydrological cells at various sizes, ranging from first to sixth order, as the unit of measure. This approach is presented as an alternative to the box-counting method as it may be much more representative of hydro-ecological processes at catchment scales. Multifractal spectra are generated for each landscape property and spectral parameters such as the range in $\alpha$ (Holder exponent) values and maximum dimension at $\alpha_{0}$, (also known as the capacity dimension $D_{\text {cap }}$ ), are obtained. Other fractal dimensions (information $D_{i n f}$ and correlation $D_{c o r}$ ) are also calculated and compared. The dimensions are connected by the inequality $D_{c a p} \geq D_{i n f} \geq D_{c o r}$. Such a relationship strongly suggests that the landscape patches are heterogeneous in nature and that their scaling behaviour can be described as multifractal. The quantitative parameters obtained from the spectra may provide the basis for improved parameterisation of ecological and hydrological models.
\end{abstract}

Key words: fractal, multifractal, scaling, landscape, patchiness

\section{Introduction}

Many terrestrial processes are modified or influenced by the interaction of landscape patterns with the process. For example, hydrological response to rainfall depends on, amongst other factors, the variability of landscape properties such as vegetation cover, soil types and the underlying geology of the terrain. The nature of this variability is scaledependent and affected by a variety of landscape properties that are the sources of the variability. To understand this variability, heterogeneity must be investigated and quantified with respect to scale. In a previous study (Nikora et al., 1999) "bulk" landscape patterns were examined for the North and South Islands of New Zealand using landscape data on soils, vegetation, hydrogeology and topography. Fractal analysis revealed scaling at two structural levels: (i) individual patch level and (ii) mosaics (sets) of patches, and furthermore, the scaling properties of individual patches influence those for mosaics of patches, and vice versa.

Patch shapes showed self-similarity at smaller scales but increasing self-affinity at larger scales. Scaling is said to be self-similar if rescaling is equal in all directions (isotropic), but self-affine if the objects scale differently in the horizontal and transverse directions (anisotropic).

In this study, the focus is on the "catchment" scale and the aim is to characterise the fractal and multifractal scaling properties of the same landscape properties but in the context of hydrological catchments. The additional information provided by this study should lead to an improvement of hydrological and ecological model predictions. The need for such quantitative descriptions of landscape heterogeneity 
was highlighted in earlier hydrological and ecological studies (Pearson, 1995; Milne et. al., 1992; Gardener et al., 1987). Many physically-based hydrological models use spatially distributed information on soils, vegetation and topography. However, there are limits to what can be measured in the field. Data are often interpolated or extrapolated to provide a representation of field conditions as input to these models. Many of these efforts result in only marginally better and sometimes worse correspondence with measured values, partly due to the variability of such input data. It is believed that if the nature of this variability is understood and quantified appropriately then model predictions would improve (Seyfried and Wilcox, 1995; Puigdefabregas and Sanchez, 1996). Therefore, the aim of this study is to quantify each landscape property examined previously and to investigate how it changes with scale from the smallest catchment (sub-basin), enclosing "single" streams, to the largest catchment of the river system. Two river systems of the west coast of the South Island of New Zealand were chosen - the Grey and Buller catchments each draining several thousand square kilometres. Landscape data derived from a national land resource database (Newsome, 1992) were analysed using different fractal methods. The analysis begins by examining the scaling behaviour of "bulk" properties using a monofractal approach, following the hypothesis that landscape properties demonstrate fractal scaling within the context of catchments, in a similar way to a previous study of landscape patchiness in New Zealand (Nikora et al., 1999). Next, the hypothesis that scaling is more likely to be multifractal than monofractal is examined. Strong hints of non-monofractal behaviour were suggested in the previous study, and further, it is known that cascading terrestrial processes can possess an infinite number of singularities (many dimensions) on a given substrate (which may also have its own and separate fractal dimension).

Recent studies ( Rinaldo et al., 1992; Rigon and Rinaldo, 1993) show that such behaviour is exhibited by important hydrological variables such as slopes, contributing areas, width functions, etc. It would therefore be expected that other terrain properties would also show such behaviour.

\section{Data}

\section{CHANNEL NETWORK AND CATCHMENT}

\section{BOUNDARY EXTRACTION}

Two neighbouring catchments, the Buller $\left(6370 \mathrm{~km}^{2}\right)$ and the Grey $\left(3910 \mathrm{~km}^{2}\right)$, located in the northern part of the west coast of the South Island of New Zealand (Fig. 1) were chosen for this study. The basins were chosen not for a comparative study of their properties but rather to illustrate and study their heterogeneity. The two examples offer unique landscapes for study because they have remained largely untouched by anthropogenic effects. Large variations in landform are found in these basins, and are the result of wide-ranging lithology, vegetative cover, and an annual rainfall that is one of the highest in New Zealand. The geomorphology of the basins is determined largely by their tectonic setting, to the west of the Southern Alps and the Alpine Fault (SW to NE orientation). Fault lines also splay onto areas of the Buller basin. The lithology ranges from granite to greywacke, passing into schist, which becomes increasingly metamorphosed at the Alpine Fault. The proximity of the basins to the mountainous divide results in high rainfall, brought by prevailing warm westerlies. Rainfalls as high as $8000 \mathrm{~mm}$ per annum have been recorded in this region. Typically, for the Buller the range is from 1500 to $6000 \mathrm{~mm} \mathrm{yr}^{-1}$ and $2000-5000 \mathrm{~mm} \mathrm{yr}^{-1}$ for the Grey. The high rainfall and mild year-round temperatures have resulted in luxuriant vegetative cover of both native and planted forests up to an elevation of $1000 \mathrm{~m}$, with scrub and mountainous vegetation above that. Pockets of other vegetation are found in the flatter coastal areas. The rivers are large and steep, and the landscape is characterised by steeply sloping hillsides that drain into gravel riverbeds.

Catchment (sub-basin) boundaries for the two basins were extracted, firstly by processing $20 \mathrm{~m}$ contours (Land Information New Zealand, 1999) into a $30 \mathrm{~m}$ DEM using TOPOGRID which is available within the GIS Arc/Info (ESRI, 1992). Once the DEM was obtained and pit filled (i.e. areas of cells that are completely surrounded by cells of higher elevation are raised to the elevation of their lowest neighbour), it was processed further using software provided by D.G. Tarboton (Utah State University). The simplest and most common method for defining flow directions is based on the use of a single support area threshold, combined with a D8 flow direction method. More recently, methods that involve partitioning of the flow between multiple neighbouring cells (Tarboton, 1997) have been used, together with alternative methods of thresholding (e.g. using slope and contributing areas, Montgomery and FoufoulaGeorgiou, 1993), and by using a threshold obtained from locally upward curved grid cells (Peuker and Douglass, 1975). For the two basins in this study it was found that the best river networks are obtained by using the PeukerDouglass upward curved grid cells approach (Tarboton and Shankar, 1998). This was done by examining slope-area plots and statistics of elevation drops in Strahler-ordered streams, and further by subjective comparison of contour crenulations. Once the channel network was obtained from the DEM it was imported into Arc/Info, and ordered using 


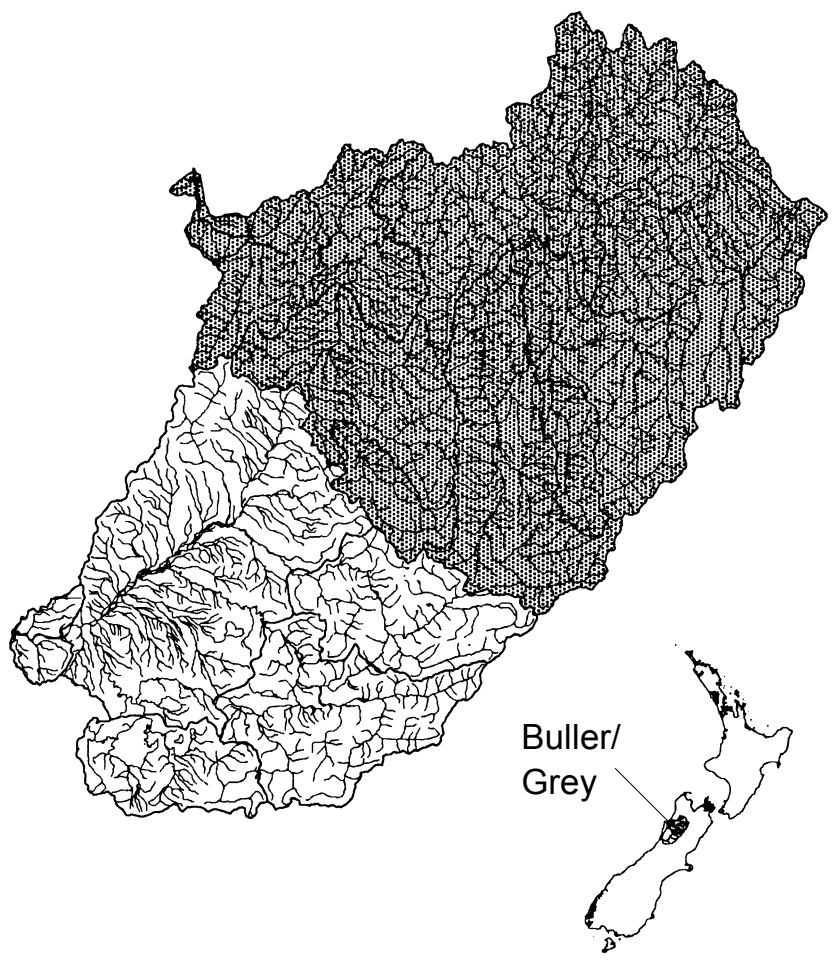

Fig. 1. Map showing the location of the catchments studied.

the Strahler ordering system. Sub-basin boundaries were delineated at every node intersection (i.e. where two or more channels meet) and the resulting catchments assigned stream orders based on the main channel segment within each boundary.

Landscape properties for New Zealand are available from the New Zealand Land Resource Inventory (NZLRI) (Newsome, 1992). Use of the data and extraction of relevant properties for study were described in a previous paper (Nikora et al., 1999) and are listed in Table 1. In the earlier study the spatial distribution of these patches was examined within the context of New Zealand as a whole whereas, here within catchment, patch distributions are examined for the two catchments. Sub-basins of the catchments were extracted, ranging from first order to sixth order for the Buller and first to fifth order for the Grey. Using the GIS, basins were overlaid on the derived channel network and landscape patches. A total of 8555 sub-basins in the Buller and 4878 sub-basins in the Grey, ranging from $0.5 \mathrm{~km}^{2}$ to $981 \mathrm{~km}^{2}$, were analysed. The number of patches analysed for each landscape property (Table 1) ranged from 11800 for "minimum porosity" of soil for the Grey to 28000 for the slope category for the Buller. The sub-basin properties determined are listed in Table 2 and illustrated diagrammatically in Fig. 2.

\section{Method}

Intuitively, one would expect the movement and distribution of freshwater on land to be influenced by the myriad of landforms and the heterogeneous nature of landscape patterns. Indeed, hydrological and ecological studies in the past have highlighted this influence and the need to incorporate the heterogeneity in both spatial and temporal studies of these processes (Pearson, 1995; Seyfried and Wilcox, 1995; Becker and Braun, 1999). To characterise landscape heterogeneity questions such as: "what landscape properties are responsible for the apparent heterogeneity observed in landscapes, and how and at what scales do they manifest themselves?" should be addressed.

One approach is fractal analysis (Mandelbrot, 1977; Goodchild and Mark, 1987; Milne, 1991), which offers a means by which landscape properties can be quantified and characterised. Rodriguez-Iturbe et al. (1994) used selforganised criticality (SOC) concepts to show that landscape evolution through erosive and diffusive processes gives rise to modelled landforms which show fractal and multifractal (characterised by a hierarchy of fractal dimensions) behaviour. This is reflected in the fractal scaling properties exhibited by stream lengths (Nikora et al., 1996; Tarboton et al., 1988 ) and accumulated areas (Nikora et al., 1999; Rinaldo et al., 1992 ). Multifractal behaviour was shown by Rodriguez-Iturbe et al. (1994) to be the result of spatially variable field properties, which reflect the interaction of the soil mantle with, for example, geology and climate amongst other factors. In an earlier study of landscape scaling properties (Nikora et al., 1999) it was found that patches of landscape properties (for example soils, vegetation, hydrogeology and topography) showed scaling behaviour that was fractal in nature. Similarly, mosaics of these patches also showed fractal scaling in patch area and boundary distribution, and further, this scaling behaviour was influenced by individual patches and vice versa.

This study therefore attempts to answer these questions through the following investigations:

(1) scaling of all catchment properties (both morphometric and landscape);

(2) scaling at increasing sub-basin orders, and finally;

(3) a multifractal analysis of all properties.

\section{SCALING IN CATCHMENT PROPERTIES}

\section{(a) Morphometric parameters}

The scaling behaviour of channel networks is studied using previously established methods (Nikora and Sapozhnikov, 1993a; Nikora et al., 1996). The method uses relationships which connect longitudinal $(l)$ and transverse $(w)$ scales of 
Table 1. Description of landscape patch types and classes.

\begin{tabular}{|c|c|c|c|c|c|}
\hline Patch type & Class & Description & Patch type & Class & Description \\
\hline \multirow[t]{22}{*}{ Slope } & 1 & $0-3 \mathrm{deg}$ & \multirow[t]{6}{*}{ Erosion } & 1 & negligible \\
\hline & 2 & $0-3 \mathrm{deg}$ and dissected & & 2 & slight (1-10\% of land affected) \\
\hline & 3 & $0-3$ deg mixed & & 3 & moderate $(11-20 \%)$ \\
\hline & 4 & $4-7$ deg & & 4 & severe $(21-40 \%)$ \\
\hline & 5 & 4-7 deg and dissected & & 5 & very severe $(41-60 \%)$ \\
\hline & 6 & 4-7 deg mixed & & 6 & extreme $(>60 \%)$ \\
\hline & 7 & $8-15 \mathrm{deg}$ & \multirow{8}{*}{$\begin{array}{l}\text { Hydrogeological } \\
\text { properties }\end{array}$} & 1 & very low \\
\hline & 8 & $8-15 \mathrm{deg}$ and dissected & & 2 & low \\
\hline & 9 & $8-15$ deg mixed & & 3 & high low \\
\hline & 10 & $16-20 \mathrm{deg}$ & & 4 & medium \\
\hline & 11 & $16-20 \mathrm{deg}$ and dissected & & 5 & high medium \\
\hline & 12 & 16-20 deg mixed & & 6 & high \\
\hline & 13 & $21-25$ deg & & 7 & medium high \\
\hline & 14 & $21-25 \mathrm{deg}$ and dissected & & 8 & very high \\
\hline & 15 & $21-25$ deg mixed & \multirow[t]{7}{*}{ Soil drainage } & 1 & very poorly drained soil \\
\hline & 16 & $26-35 \mathrm{deg}$ & & 2 & poorly drained \\
\hline & 17 & $26-35 \mathrm{deg}$ and dissected & & 3 & imperfectly drained \\
\hline & 18 & $26-35$ deg mixed & & 4 & moderately well drained \\
\hline & 19 & $>35 \mathrm{deg}$ & & 5 & well drained \\
\hline & 20 & $>35 \mathrm{deg}$ and dissected & & 6 & high-excessively drained \\
\hline & 21 & $>35$ deg mixed & & 7 & excessively drained \\
\hline & & & Depth weighted & 1 & $1-3 \%$ volume \\
\hline \multirow[t]{13}{*}{ Vegetation } & 1 & bare land & macroporosity & 2 & $4-6 \%$ \\
\hline & 2 & short grass & \multirow[t]{5}{*}{ of soil } & 3 & $7-9 \%$ \\
\hline & 3 & long grass & & 4 & $10-12 \%$ \\
\hline & 4 & short crops & & 5 & $13-15 \%$ \\
\hline & 5 & tall crops & & 6 & $16-20 \%$ \\
\hline & 6 & short scrub & & 7 & $>21 \%$ \\
\hline & 7 & tall scrub & \multirow{7}{*}{$\begin{array}{l}\text { Minimum } \\
\text { porosity of soil }\end{array}$} & 1 & $1-3 \%$ volume \\
\hline & 8 & exotic forest & & 2 & $4-6 \%$ \\
\hline & 9 & native forest & & 3 & $7-9 \%$ \\
\hline & 10 & short weeds & & 4 & $10-12 \%$ \\
\hline & 11 & tall weeds & & 5 & $13-15 \%$ \\
\hline & & & & 6 & $16-20 \%$ \\
\hline & & & & 7 & $>21 \%$ \\
\hline
\end{tabular}

a channel network with the total length $(l)$ of the network through scaling exponents $v_{l}$ (longitudinal) and $v_{w l}$ (transverse). Further, by use of a simple law proposed by Mandelbrot (1977), the main river length $(L)$ and the total length $(L)$ of a drainage network can also be related to its area $(A)$ by:

$$
\begin{aligned}
& L \propto A^{\gamma} \\
& L \propto A^{\varepsilon}
\end{aligned}
$$

where $\gamma$ and $\varepsilon$ are scaling exponents.

By combining and rearranging equations (Nikora and Sapozhnikov, 1993a) it can be shown that:

$$
L \propto l^{1 / v_{l i}} \propto L^{v_{l} / v_{l i}} \propto\left(A^{1 /\left(v_{l}+v_{w l}\right)}\right)^{v_{l} / v_{l i}}=A^{v_{l} / v_{l i}\left(v_{l}+v_{w l}\right)}
$$

where $v_{l i}$ is similar to $v_{l}$ and relates the main channel length $L$ to the straight line projection between ends:

$$
L \propto l^{1 / v_{l i}}
$$


Table 2. Description of catchment (sub-basin) geometrical properties extracted

Description

Symbol

1. length of the longest channel inside a basin

2. the straight line distance between the ends of the channel projection

$L$

. total length of the channel network projection

4. geometric length, which is the straight line length from the outlet to the source (indicated by the crenulations of the contour) $l_{g}$

5. link length, which is the longest upstream path from a stream junction to the end of the network

6. basin area

7. the basin perimeter

8. maximum basin elevation

9. minimum basin elevation

10. maximal length of a basin, measured from its outlet

11. maximal width of a basin, orthogonal to $l_{t} \quad w$

12. area of a patch for landscape property $i$; $j$ represents its class;

13. perimeter of a patch

14. total number of patches within a basin

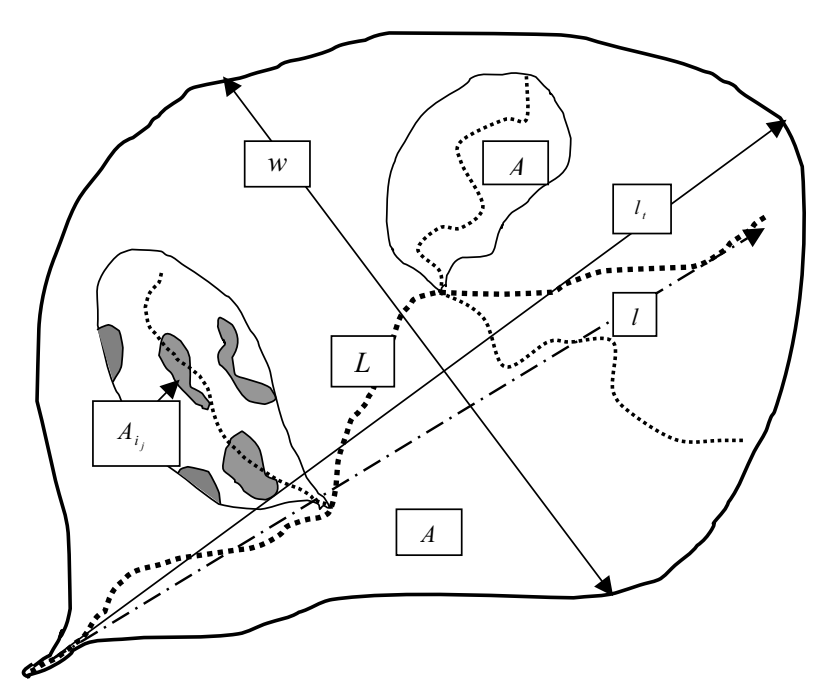

Fig. 2. Sketch showing the catchment(sub-basin) parameters used in the fractal and multifractal analysis. $L$, is the length of the longest reach in the network from source to outlet; $l$, the straight line distance between source and mouth of longest reach; $L$, the total length of the channel network in a basin; $l_{t}$, maximal straight length of a basin measured from its outlet; $w$, maximal width of a basin orthogonal to the maximal length; $A$, basin area; $A_{i j}$, area of a patch, $i$ represents a sub-basin property and $j$ the class within that property (eg. vegetation type - native forest, scrub etc.).
Exponents $\gamma$ and $\varepsilon$ can be equated as follows:

$$
\begin{aligned}
& \gamma=v_{l} / v_{l i}\left(v_{l}+v_{w l}\right) \\
& \varepsilon=1 /\left(v_{l}+v_{w l}\right)
\end{aligned}
$$

and evaluated from the regression slope of a log-log power law plot between river lengths and catchment (and subbasin) area. Scaling exponents $v_{l}$ and $v_{l i}$ are calculated from (5) and (6). In these and subsequent equations the inequality in dimensions between both sides of the equation is addressed by the introduction of a proportionality constant. The slope of the regression lines provide the dimensions that reflect the scale independent repetitions of pattern complexity and structure, which is the focus of this study.

\section{(b) Catchments}

The scaling properties of catchments are examined using a modified form of Hack's Law (Ijjasz-Vasquez et al., 1993; Rigon et al., 1996). Here maximal catchment length $l_{t}$ is related to its area by $A$ :

$$
l_{t} \propto A^{\gamma}
$$

and $\gamma$ (the same scaling exponent as in Eqn. 1) evaluated. Since area scales with length and width then:

$$
w \propto l_{t}^{H}, A \propto w l_{t} \propto l_{t}^{(1+H)}
$$

where $w$ is the catchment width (orthogonal to $l_{t}$ ) and $H$ is the scaling exponent that is related to the shape of the catchment (shape is determined by the ratio $w / l_{t}$ ). When $H=1$ the scaling is described as self-similar, and when $H<1$ self-affine (shape changes with scale $l_{t}$ ).

\section{(c) \\ Landscape patches}

Scaling relationships of landscape patches are investigated by testing the relationship:

$$
V_{i} \propto A^{a_{i}}
$$

where $V_{i}$ is the value of a landscape measure (for e.g. the total area of a forest patch within a sub-basin boundary, or the total perimeter of all forest patches inside that boundary). Table 1 lists the properties studied. 
SCALING AT INCREASING (CUMULATIVE) SUB-

\section{CATCHMENT ORDERS}

Landscape patch size and frequency are related through the following probability distribution (Nikora et al., 1999):

$$
F(a>A) \propto A^{-\beta}
$$

This expression is known as Korcak's law ( Mandelbrot, 1983), where $a$ is the patch area which is greater than some limiting area $A$, and $\beta$ is the Korcak exponent, which is usually interpreted as half of the patch fractal dimension (D). Hastings and Sugihara (1993) present examples of this approach in describing vegetation patches.

\section{MULTIFRACTAL ANALYSIS OF CATCHMENT PROPERTIES}

Previous studies (Nikora et al., 1999; Rodriguez-Iturbe et al., 1994; Goodchild and Mark, 1987) have demonstrated that many landscape properties show a multifractal scaling relationship, with the scaling behaviour described by a whole family of different exponents.

The frequency distribution of the density of a landscape measure (property) can be related to the size of the $i$-th box covering the property through:

$$
p_{i}(\varepsilon) \propto \varepsilon^{\alpha}
$$

Here the normalised probability density $p_{i}(\varepsilon)$, scales with size $\varepsilon$, (where $\varepsilon=r / R, r$ is the box size and $R$ is the region size). $\varepsilon$ provides a measure of the proportion of the variable within a box (e.g. how much mass) and $\alpha$ is a non-integer exponent known as the crowding index or Lipschitz-Holder exponent. Although $\alpha$ depends on the actual position on the fractal, there are usually many boxes with the same index. In general, the number of such boxes scales with $\varepsilon$ as:

$$
N_{\alpha}(\varepsilon) \propto \varepsilon^{-f(\alpha)}
$$

where $f(\alpha)$ is the fractal dimension of the subset of boxes characterised by the same $\alpha$ value. The function $f(\alpha)$, which is called the multifractal spectrum, gives a full description of any fractal object, including any uniform fractals. The $f(\alpha)$ spectrum for the latter is simply a single point on the $f-\alpha$ plane.

The function $f(\alpha)$ is directly connected with the so called generalised fractal dimension $D_{q}$ (Hentschel and Procaccia, 1983) which follows from the relation:

$$
\chi_{q}(\varepsilon)=\sum p_{i}^{q}(\varepsilon) \propto \varepsilon^{\tau(q)} \propto \varepsilon^{(q-1) D_{q}}
$$

where quantity $\chi_{\mathrm{q}}(\varepsilon)$ is the sum over all boxes of the $q$-th power of box probabilities (quantities), $-\infty<q<\infty$. The quantity $p$ in Eqn. (13) is a density or probability and can be substituted by any correctly scaled variable, e.g. it can be replaced by sub-basin mainstem channel length provided this is scaled by the mainstream length for the whole catchment that includes the sub-basin. The function (Grassberger and Procaccia, 1983):

$$
\tau(q)=(q-1) D_{q}
$$

is also a quantitative characteristic of multifractal objects, like $f(\alpha)$. When $q=0, D_{q=0} \equiv D$, which is the fractal dimension of the support set of the variable being studied. At the limits when $q \rightarrow \infty D_{\infty}=\alpha_{\min }$ and $\alpha_{\max }$. The latter two variables establish the extent of heterogeneity for a particular property and is often used as a measure of heterogeneity. The function $f(\alpha)$ is the Legendre transform of the function (Meneveau and Sreenivasan, 1991):

$$
f(\alpha)=q \alpha-\tau(q)
$$

where $\quad \alpha=\frac{d \tau(q)}{d q}$

The direct application of the above through the traditional box-counting method is not necessarily appropriate for studying catchment processes because of the arbitrary size of cells of scale $\varepsilon$ and the presence of distinct boundaries in the data, e.g. a ridge line. Box-counting has its drawbacks, particularly with respect to curves with intricate details (Longley and Batty, 1989). For the method to be more relevant to hydrology, the use of a special hydrological cell is proposed. This cell is a river catchment derived for all orders of the stream network. Equation 13 can be rewritten for the quantity $Q$ (which is a measure of a landscape property such as vegetation class, slope, land-use or soil type etc.) as:

$$
\chi_{q}=\sum_{i}\left[\frac{Q_{i}(a)}{\sum_{i} Q_{i}(a)}\right]^{q} \propto\left[\frac{l_{t}}{L_{t}}\right]^{\tau(q)} \propto\left[\frac{l_{t}}{L_{t}}\right]^{(q-1) D_{q}}
$$

where $L_{t}$ is the global length for the whole catchment (all of the Grey or Buller) and $l_{t}$ is an individual catchment (subbasin) length. To make Eqn. (16) workable it is modified to:

$$
\chi_{q}=\sum_{i}\left[\frac{Q_{i}(j)}{\sum_{i} Q_{i}(j)}\right]^{q} \propto\left[\frac{\bar{l}_{t j}}{L_{t}}\right]^{\tau(q)} \propto\left[\frac{\bar{l}_{t j}}{L_{t}}\right]^{(q-1) D_{q}}
$$

where $j$ is the catchment order, and $\bar{l}_{t j}$ is the average length of catchments of order $j$. Equation (17) can be used to investigate any quantification of heterogeneity relevant to 
hydrology, the main output being the generalised dimensions $D_{q}$ or the multifractal spectrum $f(\alpha)$. If the exponent $\alpha$, defined in (11) spreads over a range of values, and for each $\alpha$ the scaling Eqn. (12) holds then the landscape properties can be said to show multifractal behaviour. If $\alpha$ does not vary, then only monofractal or simple scaling behaviour is said to be displayed. In this case, both $\tau_{q}$ and $D_{q}$ will show a constant value for different values of $q$.

\section{Results and discussion}

\section{SCALING OF MORPHOLOGICAL PARAMETERS}

The scaling relationship of catchment morphometry is examined by plotting the main river lengths and total network lengths against the corresponding catchment areas (log-log plots). These are shown in Figs. 3 and 4, for both the Buller and Grey catchments. A straight line is obtained by fitting linear regression lines to all data from catchments
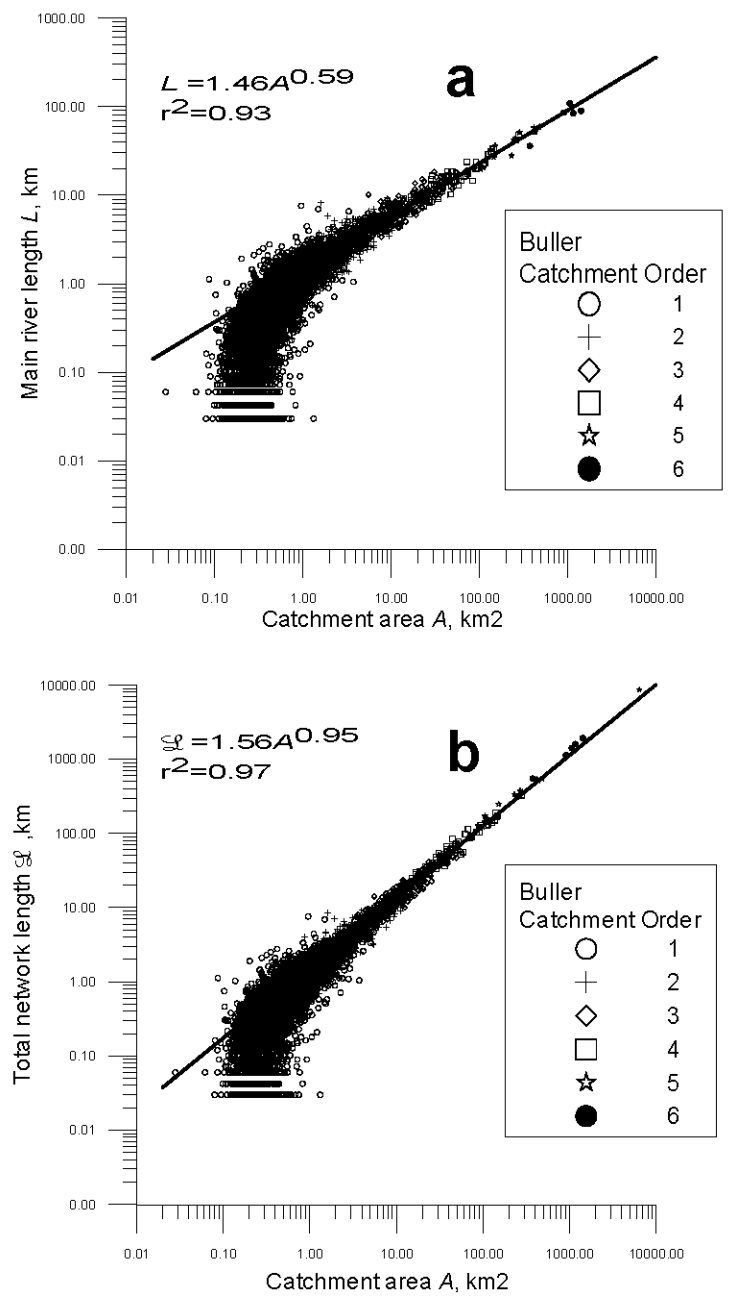

Fig. 3. Relationship of (a) main river length, and (b) total network length to catchment area for Buller. of order 3 and above. Two scaling regions are clearly distinguishable, one at areas below $1 \mathrm{~km}^{2}$ and the other above $1 \mathrm{~km}^{2}$. These results are similar to previous findings of the Hutt River study, in New Zealand (Nikora et al., 1996), and confirm the notion that river networks scale fractally with catchment area. The region below $1 \mathrm{~km}^{2}$, largely confined to first order catchments, shows a large distribution of values and no discernible scaling is apparent until what appears to be a critical area. Is this indicative of multiple scaling? Results on multifractals below provide some clues.

The first set of graphs (Figs. 3, 4) give $\gamma=0.59$ for the Buller and $\gamma=0.58$ for the Grey in Eqn. (1), which is close to the exponent in Hack's empirical rule $L=\mathrm{k} A^{\gamma}$, where k is typically 1.4 and $\gamma$ is between $0.57-0.59$ (Gray, 1961). The plot of total river length against catchment area also shows the expected value of near unity for $\varepsilon$ (Nikora et al., 1996). Figure 5 demonstrates the relationship $L \propto l^{1 / v_{i}}$. A linear relationship with a value $v_{l i} \approx 1.0$, is similar to the value
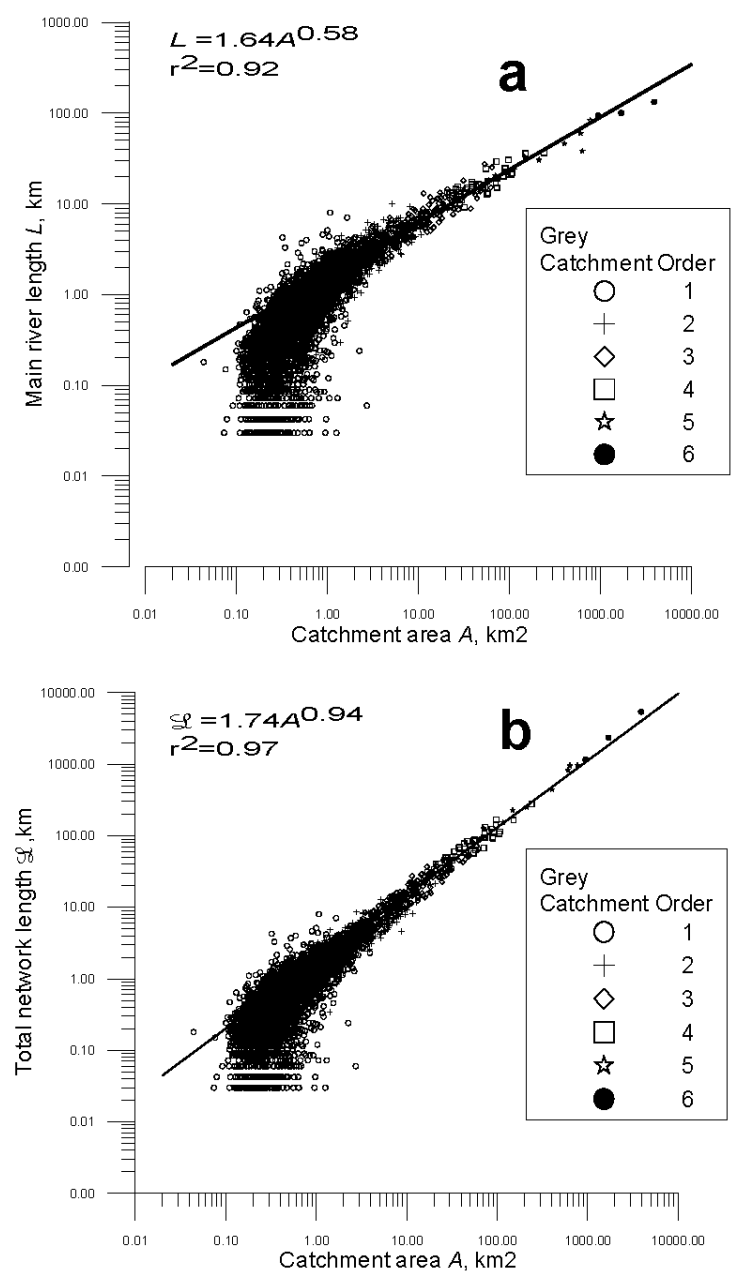

Fig. 4. Relationship of (a) main river length, and (b) total network length to catchment area for Grey. 

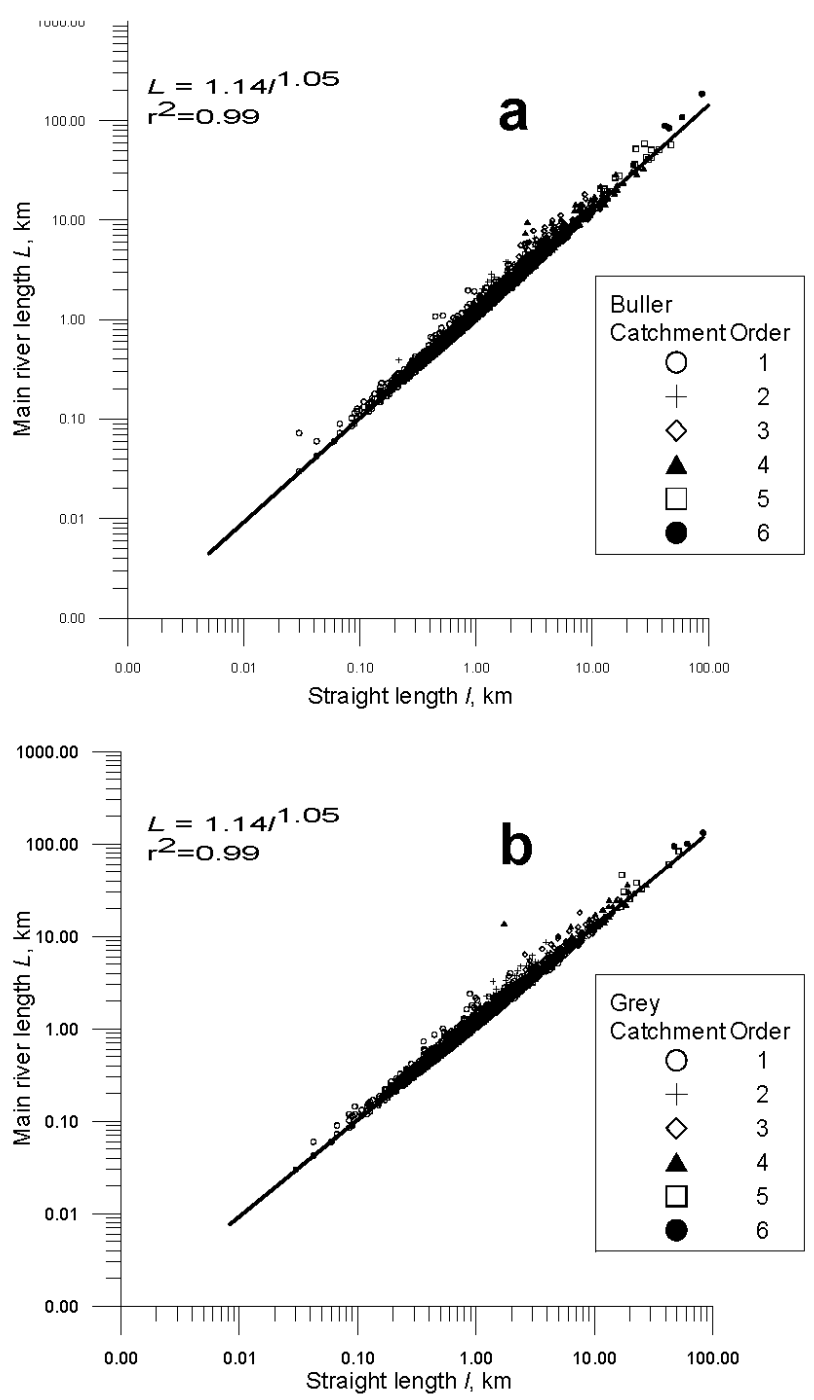

Fig. 5. Relationship of main river length with the straight line distance between ends of channel projection for (a) Buller and (b) Grey.

reported elsewhere (Nikora et al., 1996, Nikora and Sapozhnikov, 1993a). Combining these values and using Eqns. (5) and (6) $v_{l}$ is estimated as $\approx 0.6$ and and $v_{w l} \approx 0.4$ suggesting self-affinity (different scaling exponents in the longitudinal and transverse directions). The two values are close to those obtained in the previous study of the Hutt River and well within the range of values reported for other regions of the world (Nikora and Sapozhnikov, 1993b). For self-similar networks $v_{l}=v_{w l}=1 / D$, where $D$ is the channel fractal dimension. In the case where self-affinity $v_{l} \neq v_{w l}$ is shown, the fractal dimension $D_{G}$, also known as the lacunarity dimension (Turcotte, 1997), is calculated as $D_{G}=2 /\left(v_{l}+v_{w}\right) \approx 2$. This suggests a space filling network, which can also be interpreted as a geologically unconstrained (Phillips, 1993) network. The Hurst exponent, $H=v_{w l}+v_{l}$, which is also a measure of self-affinity in different directions is calculated to be 0.67 , close to reported values. The behaviour of the stream network in both of these catchments, at least at the larger scales $\left(>1 \mathrm{~km}^{2}\right)$, suggests fractal scaling with a degree of self-affinity. However, this does not preclude different scaling relationships for values below the threshold of $1 \mathrm{~km}^{2}$.

\section{SCALING OF CATCHMENT SHAPE}

Figure 6a shows a linear relationship when $\log l_{t}$ (catchment length) is plotted against $\log A$ (area). A value of $\gamma=0.51$ (Eqn. 7) is obtained for both basins. This is consistent with data obtained for basins in the United States $(\sim 0.52$ by Rigon
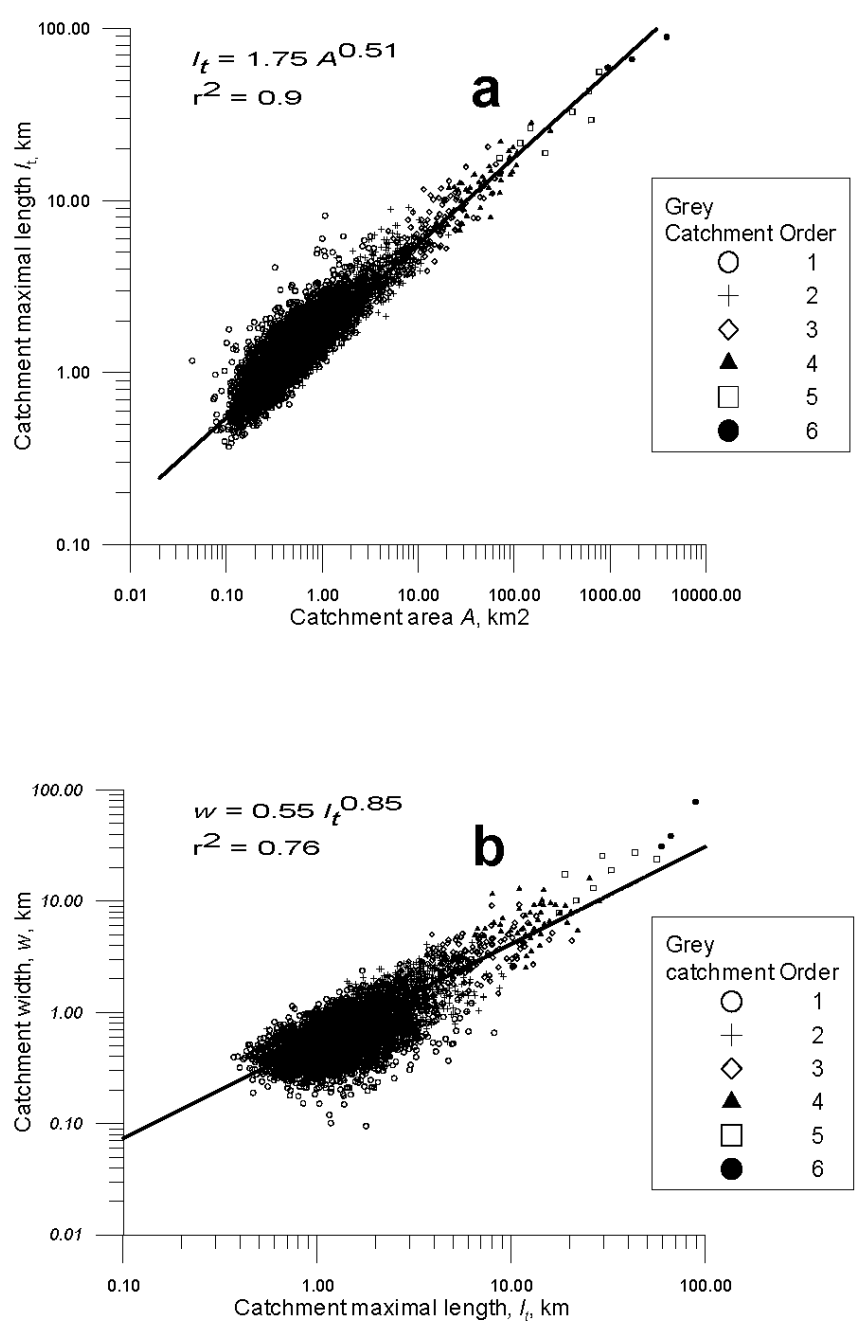

Fig. 6. Relationship between (a) catchment maximal length and catchment area, and (b) catchment width and maximal length for Grey. 
et al., 1996), and establishes that catchments in this study indeed scale fractally. Furthermore, the scaling is self-affine as indicated by a value of 0.87 (Figure 6b) for $H$ (Eqn 8). This is also consistent with previous studies (Maritan et al., 1996; Rodriguez-Iturbe et al., 1997) and indicates that the shapes of catchments are determined by different scaling exponents in the transverse and longitudinal directions and suggests a tendency for elongation as the catchment gets larger.

\section{SCALING OF LANDSCAPE PATCHES}

A similar test of scaling relationships following relationship (9) above is shown in Fig. 7. Here total area of vegetation patches inside respective catchment boundaries is plotted against catchment area. A linear regression line through the points produces a poor fit with an $\mathrm{r}^{2} \approx 0.3$. This was found to be true with every landscape property investigated in Table 1. The spread of data was too wide for a reasonable straight line to be drawn through them suggesting that scaling may be more appropriately analysed by multi-scaling or multifractal techniques. Previous studies of scaling of landscape patches (Nikora et al., 1999) has shown that a threshold occurs at about $1 \mathrm{~km}^{2}$ below which scaling of landscape patches is less readily defined than those of larger catchments using the monofractal approach.

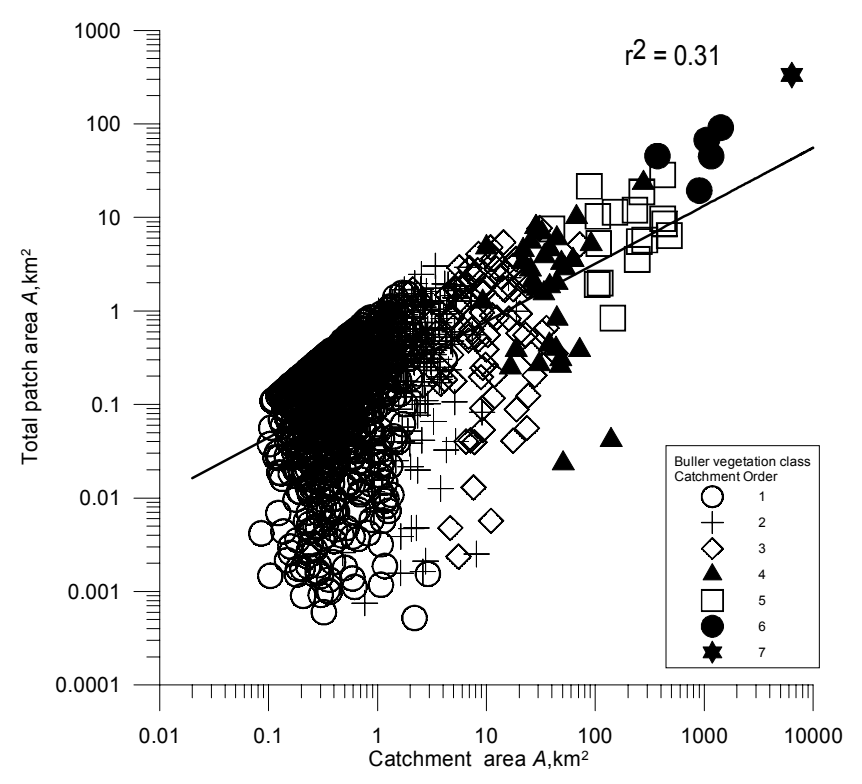

Fig. 7. Graph shows the scatter in data when areas of vegetation patches are plotted against the catchment area for the Buller.

\section{SCALING AT INCREASING SUB-CATCHMENT}

\section{ORDERS}

The possibility that landscape scaling exponents may be distributed over a range of values is also investigated. Patch areas are ranked first by sub-dividing the landscape properties into their respective classes and then plotting the logarithm of the number of patches $(N)$ in each class against the logarithm of the catchment area $(A)$, as per Eqn. (10), where $N$ is the number of sample exceedances of area $A$. Figure 8 shows a plot of the cumulative probability distribution of $N$ against catchment area for vegetation classes between 1 and 11. (Note that in the Grey catchment only 8 of the 11 possible vegetation classes occur and these are the ones given in the figure legend). A power law distribution, as in Eqn. (10) appears to be followed at the middle ranges of the dataset $\left(1 \mathrm{~km}^{2}\right.$ to $\left.100 \mathrm{~km}^{2}\right)$, but not for all of the data. Scaling at intermediate regions yield $\beta$ (Korcak's exponent) values between $0.70 \pm 0.25$ and 0.88 \pm 0.13 . Previously reported values are in the range 0.64 to 0.75 (Nikora et al., 1999) for landscape patches spread over the whole of New Zealand. One difference between the two sets of values may be because catchments are used as the largest limiting area as opposed to the coastline of the North or South Island of New Zealand. These results indicate that (i) landscape patches demonstrate fractal scaling behaviour and (ii) different types of patches scale differently within a catchment.

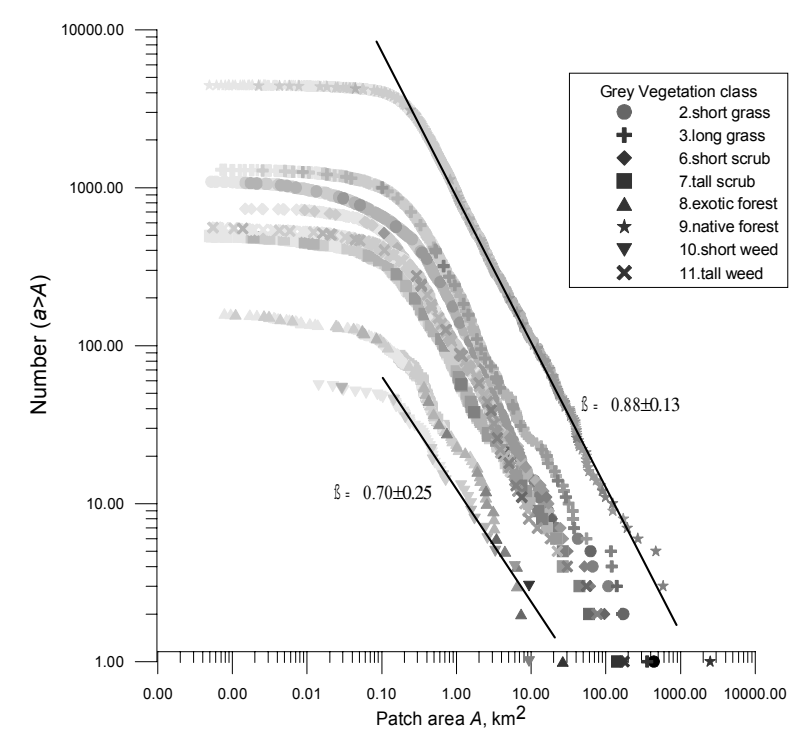

Fig. 8. An example showing the scaling relationship of Grey vegetation patch size (a) at increasing catchment areas for a range of vegetation types. This is a plot of log of the number of patches exceeding a catchment of area $A$. A best fit line was drawn in the region of intermediate catchment areas $\left(1-100 \mathrm{~km}^{2}\right)$ and slopes determined. 


\section{MULTIFRACTAL ANALYSIS}

Following Eqn. (17), the log normalised areas or perimeters of landscape properties were plotted against log normalised values of catchment(sub-basin) length (normalisation is with respect to whole catchment value), i.e.

$\log \sum_{i}\left[\frac{Q_{i}(j)}{\sum_{i} Q_{i}(j)}\right]^{q}$ versus $\log \frac{\bar{l}_{t j}}{L_{t}}$, where, $\sum_{i} Q_{i}(j)$ is the total area or perimeter of the whole catchment and $L_{t}$ is the maximal catchment length (see Fig. 2). $Q_{i}(j)$ represents areas or perimeters of patches of a particular class of slope, vegetation etc. (Table 1), at every sub-basin of order $j$, or network morphometric parameters such as the main length, total length, minimum and maximum elevation etc.(Fig. 2). Double log plots show a linear relationship between the landscape property and the normalised catchment length. By fitting straight lines through the points for each series derived for the $q$ th. scaling moment (Fig. 9) $\tau_{q}$ can be obtained (Eqn. (17)), for $q$ ranging from -10 to +10 . A non-linear relationship is observed as shown in Fig.10a.

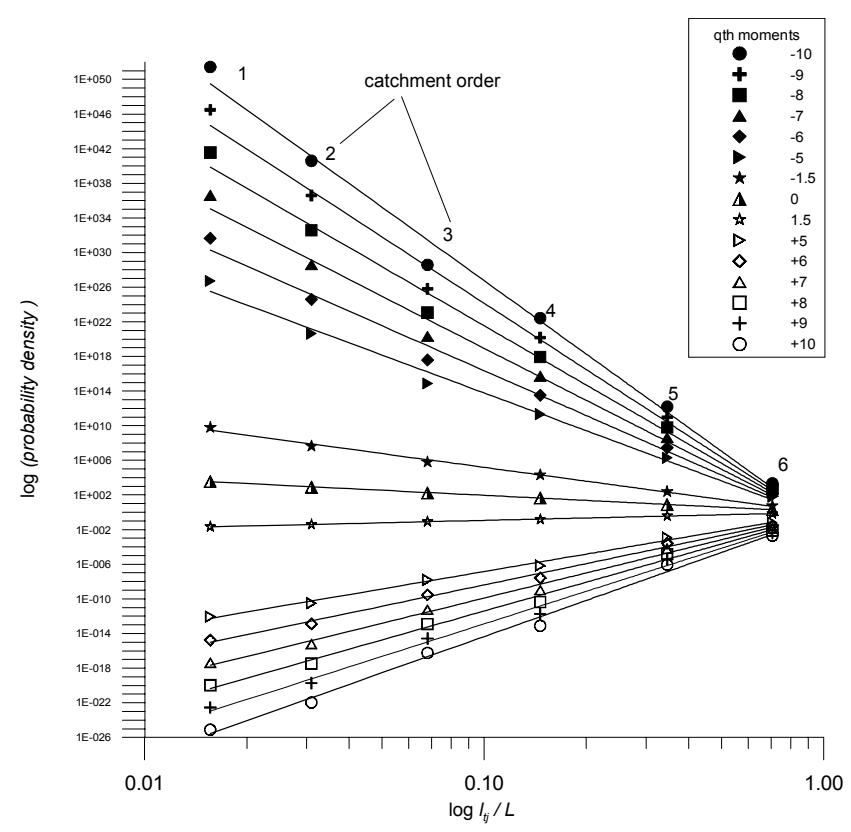

Fig. 9. Example showing the scaling of probability densities

$\left(_{i}\left[\frac{Q_{i}(j)}{\sum_{i} Q_{i}(j)}\right]^{q}\right)$ of the length of the longest channel inside basins of

the Buller catchment against the normalised catchment lengths

$\left(\frac{\bar{l}_{t}}{L_{t}}\right)$. Each series represents the scaling of the probability density for statistical moments(q) ranging from -10 to +10 . The value at each catchment(sub-basin) order is marked. A slope, $\tau_{q}$, was determined for each line.
The generalised fractal dimension $D_{q}$ is obtained next by using Eqn. (14). Plots of both $\tau_{q}$ and $D_{q}$ against $q$ are shown for an analysis of drainage area for the Buller catchment (Fig. 10). Here $\tau_{q}$ (Fig. 10a) and $D_{q}$ (Fig. 10b) plot as nonlinear curves with increasing $q$, suggesting a multifractal relationship with increasing scaling moments. If only simple scaling (monofractal), or non-invariant scaling was involved then a linear relationship would be observed between $\tau_{q}$ and $q$ in Fig. 10a and $D_{q}$ would show a constant value in Fig. $10 \mathrm{~b}$.

Equation (15) shows that $\alpha$ (the Holder exponent) can be determined from the slope of $\tau_{q}$ versus $q$ plots. The $\alpha$ values are obtained by estimating the tangent to the curve for a range of $q$ values. The intercept of each tangent line with the $\tau_{q}$ axis gives $f(\alpha)$ values, by Eqn. (15). Both quantities are determined objectively using a cubic-spline or quadratic curve (where appropriate) fitting software routine, which produced $f(\alpha)$ and $\alpha$ values as outputs. Examples of the resulting plots are shown in Figs. 10c and 11. In Fig. 11 curves were drawn over the resulting points to produce parabolas known as multifractal spectra for a range of river morphometric variables for the Grey catchment (Eqn. (11a)) and vegetation patches in the Buller catchment (Eqn. (11b)). For each curve the maximum value corresponds to the fractal dimension $f\left(\alpha_{0}\right)$ of the support (the geometric space in which the multifractal is embedded), i.e. where $q=0$. The right hand side of the curve shows values corresponding to scaling moments when $q<0$ and the left hand side corresponds to values when $q>0$. If the landscape property or variable under study scales simply (monofractal) then all values of $D_{q}$ will be the same for all $q$ as stated earlier, and both $\alpha$ and $f(\alpha)$ values will plot as a single point on the graph.

The validity of the multifractal spectrum and the inherent errors from the different numerical procedures have been highlighted and discussed by others (Veneziano et al., 1995; Rodriguez-Iturbe et al., 1997). However, it is generally agreed that the quantities $\alpha_{\max }, \alpha_{\min }, f\left(\alpha_{0}\right)$ characterise the multifractal property of a measure and carry valuable scaling information.

Multifractal curves are calculated for the catchment morphometry variables and catchment landscape properties using the above procedure. The graphs for morphometry appear to be in two distinct groups, one set belonging to river network measures such as straight line length, total length and geometric length and the other set characterising catchment maximal length and width. Both graphs peak at values close to 2 ("space filling" or Euclidean support dimension), but their $\alpha_{\max }$ and $\alpha_{\min }$ values differ significantly. The former result is also close to the data reported recently by De Bartolo et al. (2000) for river networks extracted from Calabrian basins. In that study, (multifractal spectra 

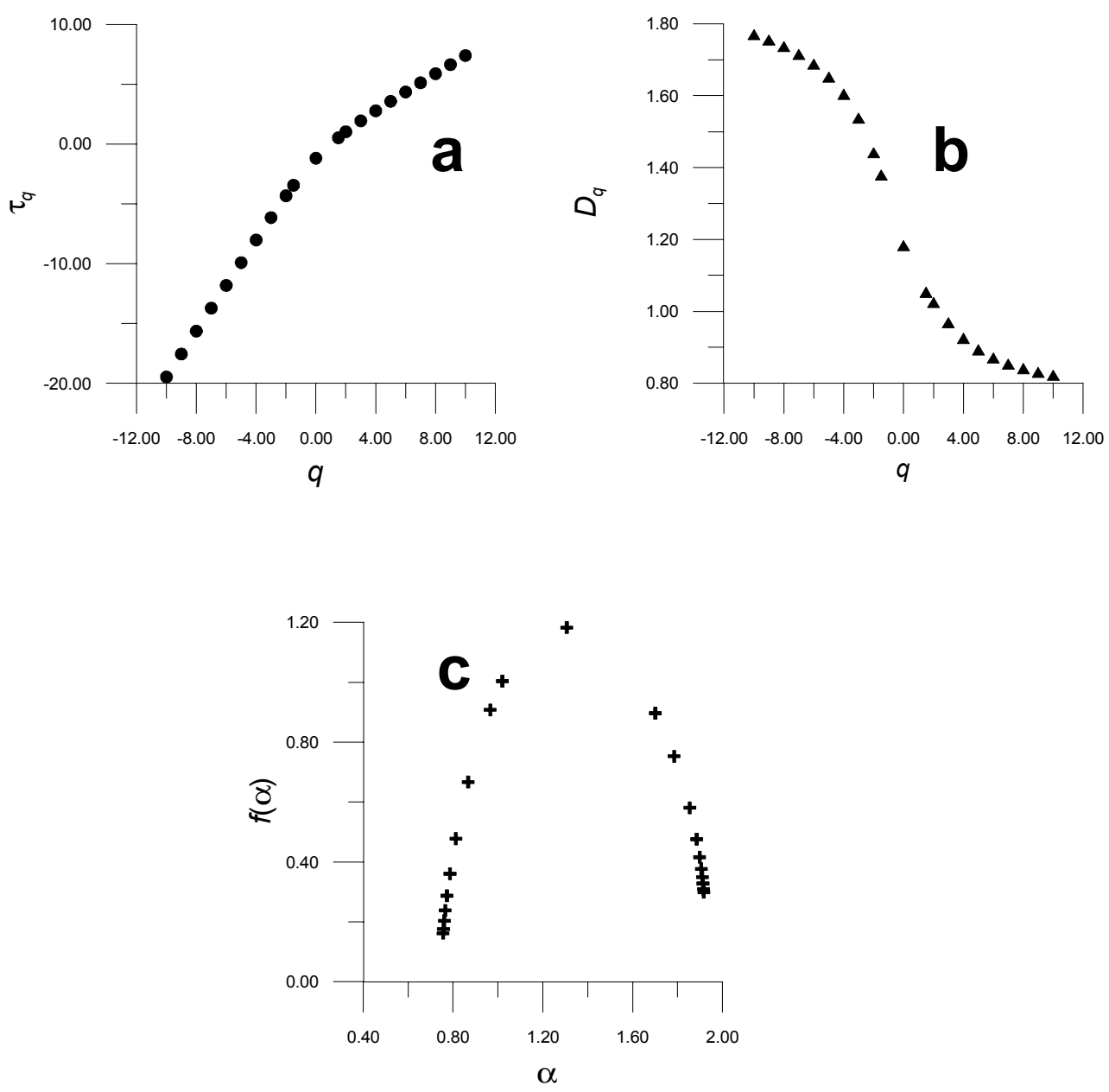

Fig. 10. Scaling of fractal dimensions. (a) shows the relationship of slope $\tau_{q}$ with $q$ (we would expect a linear relationship if only simple scaling was observed), (b) shows the scaling of generalised fractal dimension $D$ with moment $q$, and (c) demonstrates a multifractal spectrum, showing the relationship of the computed $f(\alpha)$ values against $\alpha$ (Holder exponent). Example is for Grey vegetation type 7 (tall scrub).

were obtained using a box-counting technique) the Lipschitz-Holder exponent, $\alpha$, was found to be between 1.43 and 1.86, and the support dimension, $f\left(\alpha_{0}\right)$, between 1.76 and 1.89. In contrast to catchment morphometry, landscape patch spectra here show peak values (corresponding to $f\left(\alpha_{0}\right)$ ) that ranged from 0.61 to 1.91 and $\alpha$ values between 0.1 and 3.8. There are also significant differences between each class of landscape property. This is also reflected by the range of $\beta$ values determined by examining the patch area exceedances, as described earlier and shown in Fig. 8. The physical distribution of patches on a landscape can be quantified by the range in $\alpha$ values (i.e. $\alpha_{\max }-\alpha_{\text {min }}$ ). The larger the range in $\alpha$, the greater the heterogeneity. This is because the left hand side of the spectrum emphasises the highly packed (by patches) regions and the right hand side emphasises the regions where there are gaps. When the distribution is more even, a narrowing of the curve is observed with the $f\left(\alpha_{0}\right)$ value getting closer to the space filling Euclidean dimension of the support. Tables 3 and 4 list the values of $\alpha_{\text {max }}, \alpha_{\text {min }}, \alpha_{0}, f\left(\alpha_{0}\right)\left(=D_{\text {cap }}\right), f\left(\alpha_{1}\right)\left(=D_{\text {inf }}\right)$, and $f\left(\alpha_{2}\right)\left(=D_{c o r}\right)$ for the Grey and Buller catchments respectively. $\alpha_{\max }$ and $\alpha_{\text {min }}$ were obtained by interpolation at the $f(\alpha)=0$ cutoff in the graphs (these limits approximate the $\alpha$ values at $\pm \infty$, see Eqn. 14); both $\alpha_{0}$ and $f\left(\alpha_{0}\right)$ are obtained at $\mathrm{q}=0$, at $\mathrm{q}=1 f\left(\alpha_{1}\right)$, and at $\mathrm{q}=2 f\left(\alpha_{2}\right)$. The last three fractal dimensions are also known as the capacity dimension, $D_{c a p}$, information (entropy) dimension, $D_{i n f}$, and correlation dimension, $D_{c o r}$, respectively (Grassberger and Procaccia, 1983; Moon, 1987). When these are connected by a set of inequalities such that $D_{\text {cap }} \geq D_{\text {inf }} \geq D_{\text {cor }}$, the landscape properties are distributed heterogeneously (Grassberger and Procaccia, 1983). The homogeneous condition is observed when the dimensions are equal, i.e. $D_{\text {cap }}=D_{\text {inf }}=D_{\text {cor }}$. These results show consistently that the inequality condition is true.

The magnitude of the difference between $D_{c a p}, D_{i n f}$ and 

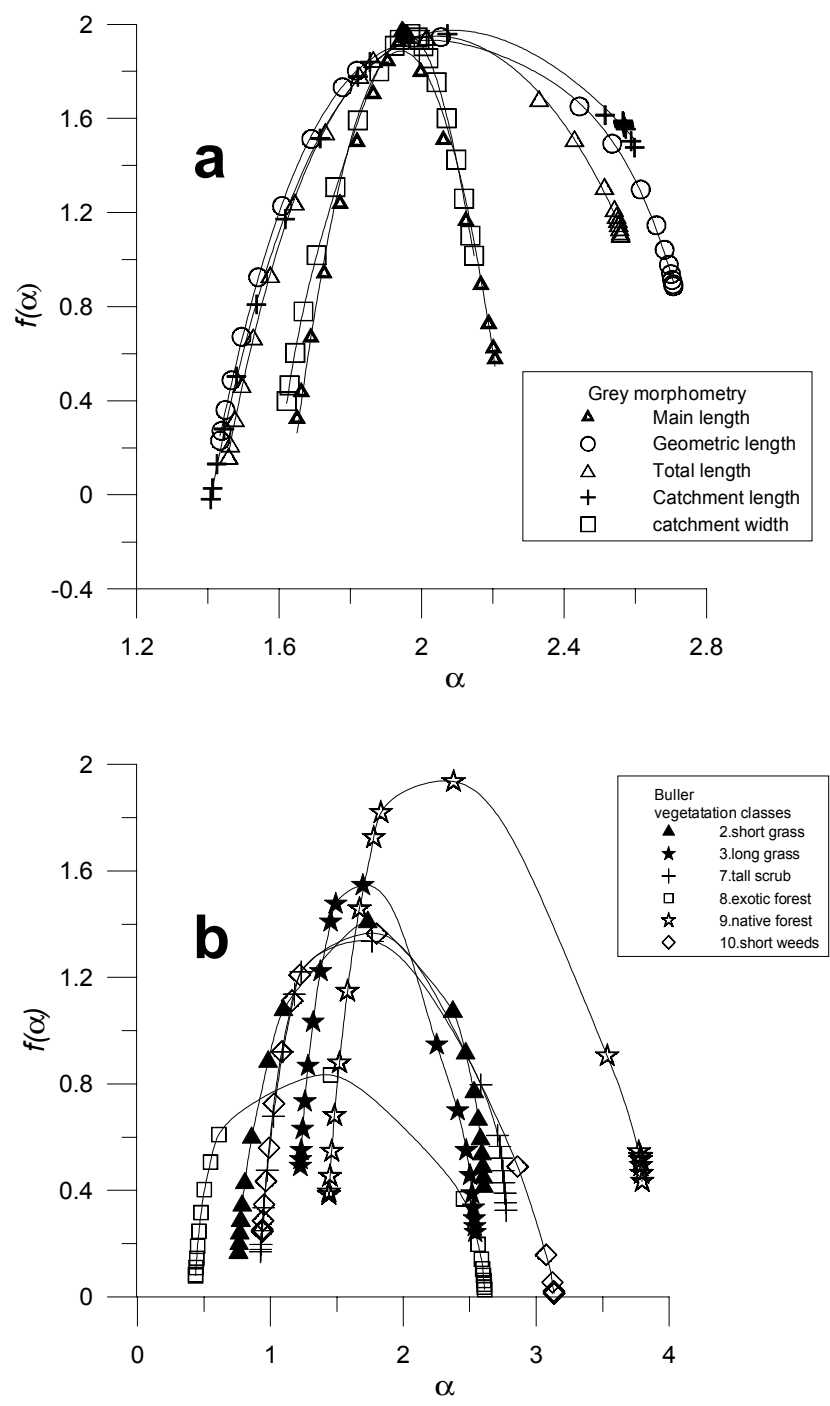

Fig. 11. Multifractal spectra obtained for (a) morphological parameters in the Grey catchment, (b) for landscape patches of vegetation types for the Buller catchment.

$D_{\text {cor }}$ may serve as a measure of heterogeneity of the landscape properties. Further, the information (entropy) dimension, $D_{i n f}$, which describes the information content of the measure (a value of 2 corresponding to a completely uniform spread), can be used to characterise the distribution of the measure in geometric space.

The range of $\alpha$ and $f(\alpha)$ values observed suggest large differences in the interaction of each class with the support. In the example shown in Fig. 11, native forest shows a significant departure from the other classes. Here, the former is more densely and evenly distributed than other types of vegetation, as shown in the map in Fig. 12. This can also be seen from the value of $D_{\text {inf }}$, which is closer to 2 than say weeds or scrub which drop down to values of around 1 . Exotic forest is in the extreme at around 0.66 for the Buller

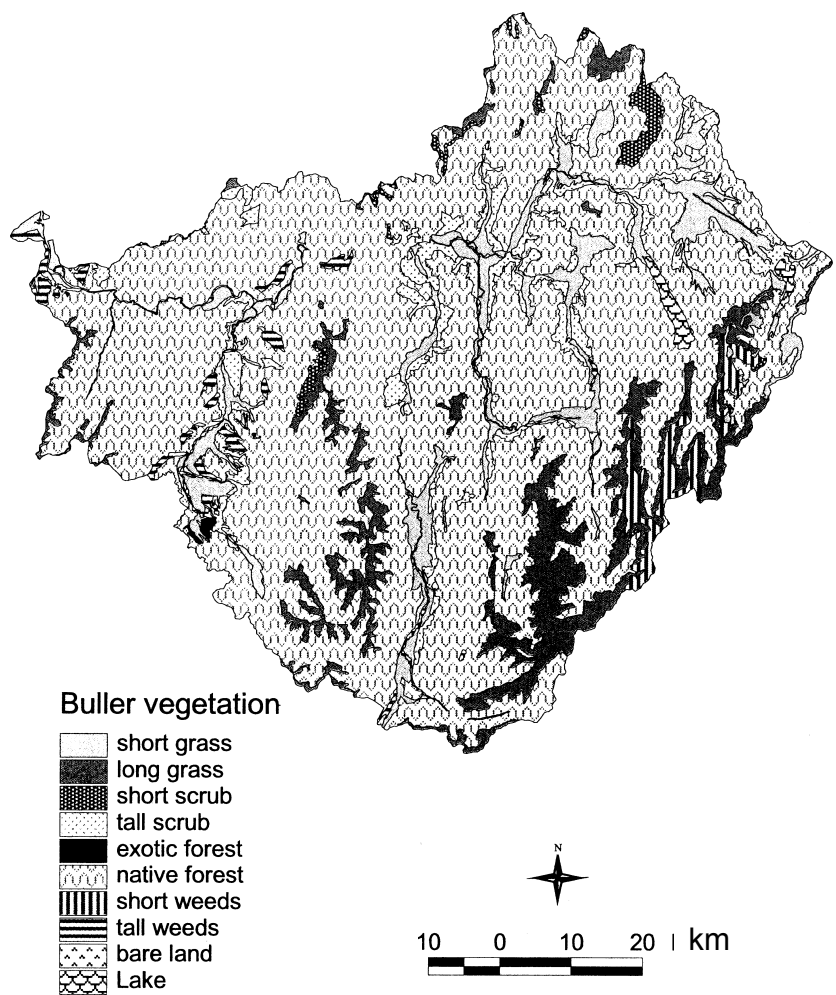

Fig. 12. Map showing the distribution of vegetation types for the Buller catchment.

and 0.95 for the Grey, reflecting its almost negligible presence in the catchments. A more significant result is the comparison of patch types that are present in nearly similar quantities in the catchment but differ in their distribution. For example, in the Buller catchment, the differences in the distribution of short grass $\left(500 \mathrm{~km}^{2}\right)$ and long grass $\left(612 \mathrm{~km}^{2}\right)$ is shown in strong contrast when the range in $\alpha$ $\left(\alpha_{\max }-\alpha_{\min }\right)$ is compared with and $D_{\text {cap }}$ values. The range is 1.83 for the former, and 0.99 for the latter. $D_{\text {cap }}$ values are 1.41 and 1.55 , respectively. Hence, the influence of landscapes with tall grass will be quantitatively different to those occupied by short grass. A much broader comparison, which may provide insights into landscape properties of catchments on a regional scale, can also be made between the two catchments. Figure 13 summarises plots of (i) the range in $\alpha$ values (width of the spectra), which quantifies the overall spatial variability of the measure in the domain, and (ii) the information dimension, $D_{i n f}$, which characterises how information increases with increasing spatial resolution, for catchment morphometry and vegetation of the two catchments. The comparisons show that both spatial variability and information content are very similar for every class of morphological or landscape parameter examined. This should not be surprising as the catchments are both adjacent to each other and largely undisturbed by any 

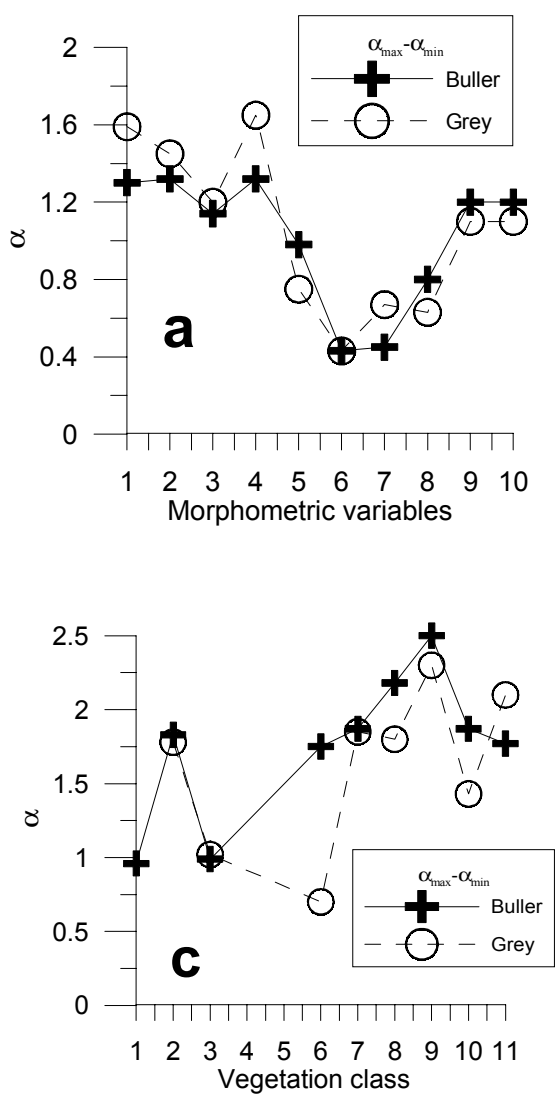
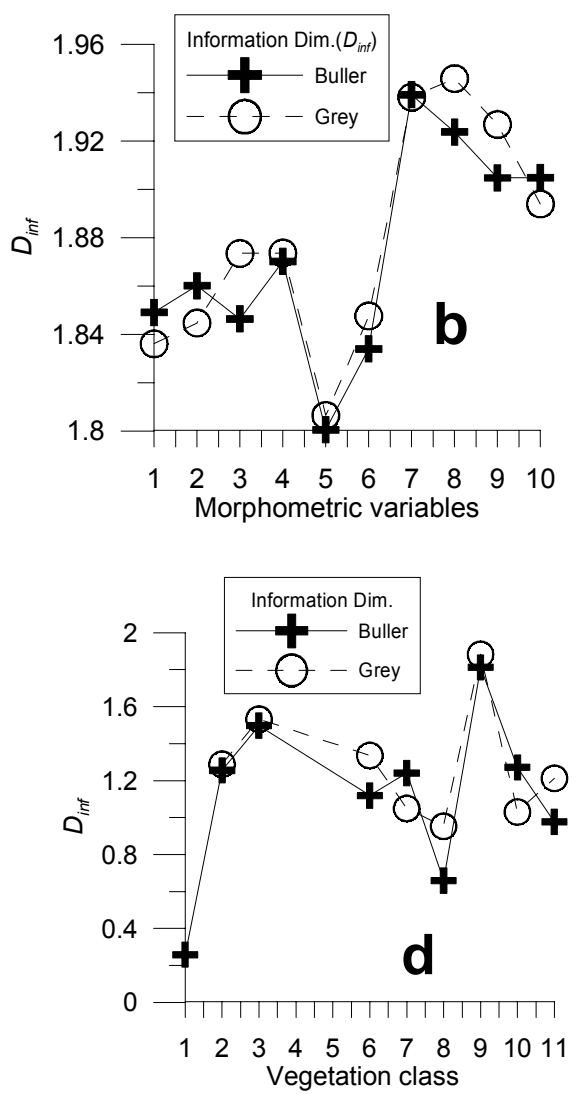

Fig. 13. Comparison of computed range in $\alpha$ values (a and c) and $\mathrm{D}_{\text {inf }}$ values ( $\mathrm{b}$ and d) between the two catchments. Note the similar trends in these values. Morphometric variables are:1-main length, 2-geometric length, 3-total length, 4-link length, 5-area, 6-perimeter,7-sub-basin length, 8- sub-basin width, 9-minimum elevation, 10-maximum elevation. Vegetation classes are:1-bare land, 2-short grass, 3-long grass, 6short scrub, 7-tall scrub, 8-exotic forest, 9-native forest, 10-short weeds, 11-tall weeds. Classes 4 and 5 are not present.

anthropogenic activity. The observed landscape patterns are the result of shaping by similar climatic conditions and the the underlying hydrogeology of the area.

Hence, the method described here can provide a tool for assessing the impact of landscape patches on hydroecological processes within catchments and potentially the quantitative comparison of catchment properties.

\section{Conclusions}

In this paper, the scaling properties of morphological and landscape variables are examined within the context of hydrological catchments using a range of landscape properties and by using both monofractal and multifractal techniques. The initial hypotheses that fractal scaling are exhibited by landscape properties within catchments, and that scaling is likely to be more multifractal than monofractal, are supported by the study.

Monofractal anlaysis shows that channel networks inside catchments scaled fractally, at least for the larger range of scales. Further, this scaling also shows a degree of self- affinity. Catchments also show similar behaviour, but are self-affine as found in previous studies. The observed scaling is well defined in the regions above $1 \mathrm{~km}^{2}$. At smaller scales $\left(<1 \mathrm{~km}^{2}\right)$ the spread of $D$ values is much greater, although the points still cluster around the fitted line. Landscape patches on the other hand could not be fitted to a straight line and it is evident that scaling is more complicated in this case. When patch areas for different properties are plotted on an exceedance probability plot of area versus the number, scaling relationships for the intermediate regions (ranging between $1 \mathrm{~km}^{2}$ and $100 \mathrm{~km}^{2}$ ) are observed, suggesting that some form of multiscaling exists for landscape patches. The novel method of using hydrological cells as "boxes" in the multifractal technique has been successful. Furthermore, multispectral curves have been derived and plotted for different properties (both morphological and landscape patches) demonstrating that multiple or multifractal scaling is indeed present. The inequality shown by the capacity, information and correlation dimensions ( $D_{c a p} \geq D_{\text {inf }} \geq D_{c o r}$ ) is a reflection of the heterogeneity (spatial variability of properties), at the scales investigated. A range of parameters 
Table 3. Characteristics of landscape properties - Buller catchment

\begin{tabular}{|c|c|c|c|c|c|c|c|c|c|c|c|c|c|}
\hline & $a_{\min }$ & $a_{\max }$ & $a_{0}$ & $D_{c a p}=f\left(a_{0}\right)$ & $D_{i n f}$ & $D_{c o r}$ & & $a_{\min }$ & $a_{\max }$ & $a_{0}$ & $D_{c a p}=f\left(a_{0}\right)$ & $D_{i n f}$ & $D_{\text {cor }}$ \\
\hline MORPHOMETRY & & & & & & & EROSION & & & & & & \\
\hline Main length & 1.42 & 2.72 & 2.03 & 1.94 & 1.85 & 1.75 & 1 & 0.89 & 3.00 & 1.82 & 1.50 & 1.32 & 1.14 \\
\hline Geom. length & 1.44 & 2.76 & 2.02 & 1.94 & 1.86 & 1.77 & 2 & 1.22 & 3.52 & 2.12 & 1.84 & 1.70 & 1.58 \\
\hline Total length & 1.38 & 2.52 & 2.02 & 1.94 & 1.85 & 1.74 & 3 & 1.10 & 3.30 & 2.01 & 1.72 & 1.57 & 1.41 \\
\hline Link length & 1.52 & 2.84 & 2.06 & 1.95 & 1.87 & 1.79 & 4 & 1.20 & 2.86 & 1.77 & 1.55 & 1.50 & 1.46 \\
\hline Area & 1.38 & 2.36 & 1.87 & 1.95 & 1.80 & 1.65 & 5 & 1.00 & 2.70 & 1.60 & 1.41 & 1.34 & 1.28 \\
\hline Perimeter & 1.64 & 2.07 & 1.86 & 1.95 & 1.83 & 1.71 & 6 & 0.94 & 2.95 & 1.67 & 1.38 & 1.28 & 1.19 \\
\hline Cat. length & 1.62 & 2.07 & 1.95 & 1.95 & 1.94 & 1.92 & & & & & & & \\
\hline Cat. width & 1.60 & 2.40 & 1.96 & 1.95 & 1.92 & 1.89 & & & & & & & \\
\hline Min. elevation & 1.60 & 2.80 & 1.97 & 1.95 & 1.90 & 1.85 & & & & & & & \\
\hline Max elevation & 1.64 & 2.84 & 1.99 & 1.95 & 1.90 & 1.85 & & & & & & & \\
\hline \multicolumn{7}{|l|}{ SLOPE } & \multicolumn{7}{|l|}{ HYDROGEOLOGY } \\
\hline 1 & 0.66 & 2.68 & 1.64 & 1.31 & 1.06 & 0.81 & 1 & 1.28 & 2.88 & 1.80 & 1.85 & 1.76 & 1.61 \\
\hline 3 & 0.47 & 1.90 & 1.24 & 0.98 & 0.77 & 0.55 & 2 & 0.60 & 2.15 & 1.21 & 0.92 & 0.83 & 0.76 \\
\hline 4 & 0.62 & 2.10 & 1.39 & 1.21 & 1.03 & 0.83 & 4 & 1.28 & 2.95 & 1.75 & 1.64 & 1.58 & 1.53 \\
\hline 5 & 0.41 & 1.33 & 0.86 & 0.76 & 0.65 & 0.53 & 6 & 0.75 & 2.55 & 1.41 & 1.17 & 1.04 & 0.92 \\
\hline 6 & 0.72 & 2.14 & 1.32 & 1.14 & 1.01 & 0.87 & 7 & 0.82 & 1.95 & 1.18 & 0.99 & 0.98 & 1.00 \\
\hline 7 & 0.44 & 0.83 & 0.63 & 0.83 & 0.64 & 0.48 & 8 & 0.82 & 2.88 & 1.90 & 1.57 & 1.32 & 1.07 \\
\hline 8 & 0.29 & 1.45 & 0.81 & 0.61 & 0.46 & 0.32 & & & & & & & \\
\hline 9 & 0.62 & 2.25 & 1.26 & 1.00 & 0.87 & 0.76 & Drainage & & & & & & \\
\hline 10 & 0.50 & 1.62 & 0.94 & 0.79 & 0.72 & 0.65 & 2 & 0.75 & 1.95 & 1.31 & 1.18 & 1.05 & 0.91 \\
\hline 12 & 0.48 & 2.46 & 1.29 & 0.87 & 0.68 & 0.52 & 3 & 0.92 & 1.95 & 1.14 & 1.17 & 1.15 & 1.09 \\
\hline 13 & 0.87 & 2.18 & 1.41 & 1.29 & 1.18 & 1.07 & 4 & 0.95 & 1.80 & 1.14 & 1.45 & 1.07 & 0.69 \\
\hline 15 & 0.80 & 2.65 & 1.49 & 1.28 & 1.18 & 1.08 & 5 & 1.30 & 3.50 & 1.99 & 1.95 & 1.84 & 1.68 \\
\hline 16 & 1.12 & 3.28 & 1.97 & 1.64 & 1.53 & 1.45 & & & & & & & \\
\hline 18 & 1.20 & 3.45 & 2.05 & 1.81 & 1.69 & 1.57 & \multicolumn{7}{|c|}{ DEPTH WEIGHTED POROSITY } \\
\hline 19 & 1.10 & 2.63 & 1.66 & 1.53 & 1.44 & 1.33 & 2 & 0.30 & 1.5 & 1.05 & 1.02 & 0.69 & 0.29 \\
\hline \multirow[t]{2}{*}{21} & 0.90 & 2.62 & 1.59 & 1.40 & 1.31 & 1.20 & 4 & 1.02 & 2.25 & 1.51 & 1.29 & 1.26 & 1.25 \\
\hline & & & & & & & 5 & 1.20 & 3.10 & 1.92 & 1.64 & 1.55 & 1.49 \\
\hline VEGETATION & & & & & & & 6 & 1.10 & 2.40 & 1.58 & 1.51 & 1.43 & 1.33 \\
\hline 1 & 0.14 & 1.10 & 0.56 & 0.36 & 0.26 & 0.17 & 7 & 1.30 & 3.80 & 2.11 & 1.90 & 1.82 & 1.72 \\
\hline 2 & 0.80 & 2.63 & 1.65 & 1.41 & 1.26 & 1.11 & & & & & & & \\
\hline 3 & 1.10 & 2.09 & 1.58 & 1.55 & 1.50 & 1.44 & & & & & & & \\
\hline 6 & 0.81 & 2.56 & 1.43 & 1.19 & 1.12 & 1.05 & MIN. POROSITY & & & & & & \\
\hline 7 & 0.95 & 2.82 & 1.64 & 1.34 & 1.24 & 1.18 & 1 & 0.32 & 1.50 & 1.05 & 1.01 & 0.68 & 0.27 \\
\hline 8 & 0.45 & 2.63 & 1.41 & 0.83 & 0.66 & 0.56 & 3 & 0.95 & 2.50 & 1.55 & 1.27 & 1.24 & 1.23 \\
\hline 9 & 1.35 & 3.85 & 2.19 & 1.94 & 1.81 & 1.69 & 4 & 1.10 & 3.20 & 1.98 & 1.65 & 1.52 & 1.42 \\
\hline 10 & 0.99 & 2.86 & 1.61 & 1.37 & 1.27 & 1.20 & 5 & 1.35 & 3.75 & 2.13 & 1.90 & 1.82 & 1.73 \\
\hline 11 & 0.75 & 2.52 & 1.36 & 1.06 & 0.98 & 0.92 & 6 & 1.05 & 3.00 & 1.77 & 1.57 & 1.43 & 1.30 \\
\hline
\end{tabular}

is obtained from the calculation of the multifractal spectra for each property is summarised in Tables 3 and 4 . Parameters such as $\alpha_{\max }, \alpha_{\min }, \alpha_{0}, D_{\text {cap }}$ and $D_{\text {inf }}$ provide a quantitative measure of the heterogeneity of each property and also provide a means of identifying and ranking the predominance (and possibly the influence) of each landscape property on various landscape processes. $D_{i n f}$, which describes the information content and hence the statistical distribution of the patches, could be a useful index for categorising vegetation cover, soil or geology for studies such as regional flood frequency estimation and regional classification of river systems (which is being used more commonly today as a tool for management of land ecosystems). 
Table 4. Characteristics of landscape properties - Grey catchment.

\begin{tabular}{|c|c|c|c|c|c|c|c|c|c|c|c|c|c|}
\hline & $a_{\min }$ & $a_{\max }$ & $a_{0}$ & $D_{c a p}=f\left(a_{0}\right)$ & $D_{i n f}$ & $D_{c o r}$ & & $a_{\min }$ & $a_{\max }$ & $a_{0}$ & $D_{c a p}=f\left(a_{0}\right)$ & $D_{i n f}$ & $D_{c o r}$ \\
\hline MORPHOMETRY & & & & & & & EROSION & & & & & & \\
\hline Main length & 1.41 & 3.00 & 2.07 & 1.95 & 1.84 & 1.72 & 1 & 1.15 & 3.40 & 2.06 & 1.75 & 1.61 & 1.49 \\
\hline Geom. length & 1.40 & 2.85 & 2.05 & 1.95 & 1.84 & 1.73 & 2 & 1.40 & 2.88 & 1.90 & 1.85 & 1.81 & 1.76 \\
\hline Total length & 1.45 & 2.65 & 2.01 & 1.95 & 1.87 & 1.78 & 3 & 1.05 & 3.00 & 1.91 & 1.61 & 1.46 & 1.30 \\
\hline Link length & 1.40 & 3.05 & 2.07 & 1.96 & 1.87 & 1.78 & 4 & 0.95 & 2.88 & 1.60 & 1.40 & 1.31 & 1.21 \\
\hline Area & 1.48 & 2.23 & 1.86 & 1.96 & 1.81 & 1.65 & 5 & 0.60 & 2.40 & 1.24 & 1.08 & 0.91 & 0.71 \\
\hline Perimeter & 1.65 & 2.08 & 1.88 & 1.96 & 1.85 & 1.73 & & & & & & & \\
\hline Cat. length & 1.58 & 2.25 & 1.97 & 1.96 & 1.94 & 1.91 & & & & & & & \\
\hline Cat. width & 1.62 & 2.25 & 1.96 & 1.96 & 1.95 & 1.93 & & & & & & & \\
\hline Min. elevation & 1.75 & 2.85 & 1.96 & 1.96 & 1.93 & 1.88 & & & & & & & \\
\hline Max elevation & 1.75 & 2.85 & 2.02 & 1.96 & 1.89 & 1.83 & & & & & & & \\
\hline SLOPE & & & & & & & HYDROGEOLOG & & & & & & \\
\hline 1 & 0.90 & 2.42 & 1.71 & 1.53 & 1.39 & 1.24 & 1 & 1.30 & 3.05 & 1.73 & 1.77 & 1.71 & 1.62 \\
\hline 2 & 0.62 & 2.30 & 1.30 & 0.99 & 0.85 & 0.74 & 2 & 1.10 & 2.22 & 1.37 & 1.42 & 1.38 & 1.30 \\
\hline 3 & 0.90 & 3.20 & 1.69 & 1.25 & 1.15 & 1.12 & 4 & 1.42 & 3.20 & 1.78 & 1.62 & 1.68 & 1.76 \\
\hline 4 & 0.82 & 2.80 & 1.61 & 1.34 & 1.21 & 1.09 & 6 & 0.65 & 1.95 & 1.33 & 1.27 & 1.07 & 0.81 \\
\hline 5 & 0.45 & 1.82 & 1.00 & 0.83 & 0.67 & 0.50 & 7 & 0.88 & 2.85 & 1.59 & 1.36 & 1.23 & 1.10 \\
\hline 6 & 0.70 & 2.00 & 1.22 & 0.99 & 0.91 & 0.84 & 8 & 1.20 & 3.45 & 2.13 & 1.76 & 1.64 & 1.55 \\
\hline 7 & 0.80 & 1.40 & 1.10 & 1.15 & 1.05 & 0.94 & & & & & & & \\
\hline 8 & 0.35 & 1.51 & 0.84 & 0.64 & 0.52 & 0.42 & DRAINAGE & & & & & & \\
\hline 9 & 0.90 & 2.20 & 1.21 & 1.26 & 1.21 & 1.13 & 1 & 0.45 & 2.20 & 1.31 & 0.83 & 0.65 & 0.54 \\
\hline 10 & 0.78 & 1.38 & 0.92 & 1.10 & 1.01 & 0.87 & 2 & 1.05 & 2.65 & 1.83 & 1.62 & 1.49 & 1.34 \\
\hline 12 & 0.80 & 2.30 & 1.46 & 1.28 & 1.16 & 1.02 & 3 & 0.95 & 1.40 & 1.17 & 1.42 & 1.13 & 0.84 \\
\hline 13 & 1.10 & 2.25 & 1.33 & 1.24 & 1.26 & 1.28 & 4 & 0.95 & 3.20 & 1.79 & 1.56 & 1.36 & 1.16 \\
\hline 15 & 0.80 & 2.65 & 1.49 & 1.20 & 1.24 & 1.12 & 5 & 1.50 & 3.60 & 2.11 & 1.93 & 1.86 & 1.79 \\
\hline 16 & 1.15 & 2.85 & 1.76 & 1.58 & 1.49 & 1.40 & & & & & & & \\
\hline 18 & 1.25 & 3.10 & 1.94 & 1.75 & 1.68 & 1.61 & \multicolumn{7}{|c|}{ DEPTH WEIGHTED POROSITY } \\
\hline 19 & 0.95 & 2.45 & 1.38 & 1.27 & 1.25 & 1.22 & 2 & 0.72 & 1.78 & 1.30 & 1.24 & 1.08 & 0.88 \\
\hline 21 & 0.95 & 2.80 & 1.54 & 1.24 & 1.16 & 1.11 & 3 & 0.62 & 2.55 & 1.48 & 1.15 & 0.93 & 0.74 \\
\hline & & & & & & & 4 & 1.10 & 2.62 & 1.67 & 1.54 & 1.43 & 1.30 \\
\hline VEGETATION & & & & & & & 5 & 1.30 & 3.30 & 2.00 & 1.73 & 1.68 & 1.66 \\
\hline 2 & 1.00 & 2.78 & 1.70 & 1.40 & 1.29 & 1.21 & 6 & 0.97 & 1.38 & 1.17 & 1.48 & 1.17 & 0.87 \\
\hline 3 & 1.18 & 2.20 & 1.50 & 1.58 & 1.53 & 1.44 & 7 & 1.30 & 3.10 & 1.88 & 1.79 & 1.72 & 1.63 \\
\hline 6 & 1.05 & 1.75 & 1.40 & 1.42 & 1.34 & 1.25 & & & & & & & \\
\hline 7 & 0.70 & 2.55 & 1.48 & 1.20 & 1.05 & 0.87 & \multicolumn{7}{|l|}{ MIN. POROSITY } \\
\hline 8 & 0.80 & 2.60 & 1.46 & 1.05 & 0.95 & 0.92 & 1 & 0.82 & 1.82 & 1.32 & 1.29 & 1.15 & 0.99 \\
\hline 9 & 1.60 & 3.90 & 2.11 & 1.92 & 1.88 & 1.86 & 3 & 0.95 & 1.35 & 1.15 & 1.44 & 1.12 & 0.81 \\
\hline 10 & 0.82 & 2.25 & 1.32 & 1.13 & 1.03 & 0.94 & 4 & 1.25 & 3.55 & 2.08 & 1.79 & 1.70 & 1.63 \\
\hline 11 & 0.90 & 3.00 & 1.63 & 1.28 & 1.21 & 1.17 & 5 & 1.30 & 3.10 & 1.88 & 1.79 & 1.72 & 1.63 \\
\hline & & & & & & & 6 & 0.98 & 3.55 & 1.89 & 1.54 & 1.34 & 1.15 \\
\hline
\end{tabular}

Hence, this type of information may be used to:

(i) develop mathematical models of ecological processes where landscape patchiness or heterogeneity is of importance (King, 1991; Milne et al., 1992; Wu and Levin, 1997). For example, King (1991) describes a variety of methods for extrapolation of model predictions. Local fine-scale models are extrapolated across heterogeneous areas by calculating an expected value of the model output from landscape area and a probability density function that describes the larger scale heterogeneity of local spatial variables. Potentially, multifractal spectra can be used to estimate this probability density function. 
(ii) develop better methodology for translating models across scales in landscapes (King, 1991; Wu and Levin 1997). The recent work of Becker and Braun (1999) is such an example. They showed that scaling laws can be applied to modelling lateral flows for both small and large basins using both simple and multifractal scaling, and demonstrated the close relationship of the scaling laws to the fractal nature of river networks.

(iii) improve methods for estimating hydrological and ecological variables within catchments by better accounting of catchment scale and heterogeneity. For example, in the recent work by Reggiani et al.(1999) on scale balance equations for Representative Elementary Watershed (REW) models, it was suggested that improved parameterisation of constitutive equations is possible through better methods for estimating spatial variability. The distribution curves provided by multifractal spectra can play a significant role in providing such quantitative input to the parameterisation of the equations, especially at scales smaller than the REW.

\section{Acknowledgements}

The research was conducted under contract C01X0010 from the Foundation for Research Science and Technology (New Zealand). The authors wish to thank Ross Woods for his valuable comments.

\section{References}

Becker, A. and Braun, P., 1999. Disaggregation, aggregation and spatial scaling in hydrological modelling. J. Hydrol., 217, 239252.

De Bartolo, S.G., Gabriele, S. and Gaudio, R., 2000. Multifractal behaviour of river networks, Hydrol. Earth Syst. Sci., 4, 105-112.

ESRI, 1992. Understanding GIS. The ARC/INFO Method. ESRI, Redlands, California.

Gardener, R.H., Milne, B.T., Turner, M.G. and O’Neill, R.V., 1987. Neutral models for the analysis of broad-scale landscape pattern. Landscape Ecol., 1, 19-28.

Goodchild, M.F. and Mark, D.M., 1987. The fractal nature of geographic phenomena. Ann. Assoc. Am. Geogr., 77, 265-278.

Grassberger, P. and Procaccia, I., 1983. Characterisation of strange attractors. Phys. Rev. Lett., 50, 346-349.

Gray, D.M., 1961. Interrelationship of watershed characteristics. J. Geophys. Res., 66, 1215-1233.

Gregory, K.J. and Walling, D.E., 1973. Drainage Basin Form and Process. John Wiley, New York.

Hastings, H.M. and Sugihara, G., 1993. Fractals. A user's guide for natural sciences. Oxford University Press, Oxford.

Hentschel, H.G.R. and Procaccia, I., 1993. The infinite number of generalised dimensions of fractals and strange attractors. Physica D, 8, 435-444.
Ijjasz-Vasquez, E.J., Bras, L.R. and Rodriguez-Iturbe, I., 1993. Hack's relation and optimal channel networks: The elongation of river basins as a consequence of energy minimization. Geophys. Res .Lett., 20, 1583-1586.

King, A.W., 1991. Translating models across scales in the landscape. In: Quantitative methods in Landscape Ecology, M.G. Turner and R.H. Gardner, (Eds.), 479-517, Springer, New York.

Land Information New Zealand, 1999. New Zealand Topo data documentation guide, version 2, Land Information New Zealand.

Longley, P.A. and Batty, M., 1989. On the fractal measurement of geographical boundaries. Geogr. Anal., 21, 47-67.

Mandelbrot, B.B., 1977. Fractals: Form, Chance and Dimension, W.H. Freeman, New York.

Mandelbrot, B.B.,1983. The fractal geometry of nature, W.H. Freeman, New York.

Maritan, A., Rinaldo, A., Giacometti, A., Rigon, R. and RodriguezIturbe, I., 1996. Scaling in river networks. Phys. Rev. E, 53, 1501-1512.

Meneveau, C. and Sreenivasan, K.R., 1991. The multifractal nature of turbulent energy dissipation. J.Fluid Mech., 224, 429-484.

Milne, B.T., 1991. Lessons from applying fractal models to landscape patterns. In: Quantitative Methods in Landscape Ecology, M.G. Turner and R.H. Gardner, (Eds.), 199-235, Springer, New York.

Milne, B.T., Turner, M.G., Wiens, J.A. and Johnson, A.R., 1992. Interactions between the fractal geometry of landscapes and allometric herbivory. Theor. Popul. Biol., 41, 337-353.

Montgomery, D.R. and Foufoula-Georgiou, E., 1993. Channel network source representation using digital elevation models, Water Resour. Res., 29, 3925-3934.

Moon, F.C., 1987. Chaotic vibrations. Wiley, New York.

Newsome, P.F.J., 1992. New Zealand land resource inventory. Arc/ Info Data Manual. Landcare Research, New Zealand.

Nikora, V.I. and Sapozhnikov, V.B., 1993a. River network fractal geometry and its computer simulation, Water Resour. Res., 29, 3569-3575.

Nikora, V.I. and Sapozhnikov, V.B., 1993b. Fractal Geometry of individual river channels and its computer simulation, Water Resour. Res., 29, 3561-3568.

Nikora, V., Ibbitt, R. and Shankar, U., 1996. On channel network fractal properties: a case study of the Hutt River basin, New Zealand. Water Resour. Res., 32, 3375-3384.

Nikora, V.I., Pearson, C.P. and Shankar, U., 1999. Scaling properties in landscape patterns: New Zealand experience. Landscape Ecol., 14, 17-33.

Pearson, C.P., 1995. Regional frequency analysis of low flows in New Zealand rivers. J. Hydrol. (NZ), 33, 94-122.

Peuker, T.K. and Douglass, D.H., 1975. Detection of surfacespecific points by local parallel processing of discrete terrain elevation data. Comput.Vision Graph., 4, 375-387.

Phillips, J.D., 1993. Interpreting the fractal dimension of river networks. In: chapter 7, Fractals in Geography, N.S.-N. Lam and L. De Cola, (Eds.), Prentice-Hall, Englewood Cliffs, N.J.

Puigdefabregas, J. and Sanchez, G., 1996. Geomorphological implications of vegetation patchiness on semi-arid slopes. In: Advances in Hillslope Processes, M.G. Anderson and S.M. Brooks, (Eds.), 1027-1060, Wiley, Chichester, UK.

Reggiani, P., Hassanizadeh, S.M., Sivapalan, M. and Gray, W.G., 1999. A unifying framework for watershed thermodynamics: constitutive relationships. Adv. Water Resour., 23, 15-39.

Rigon, R. and Rinaldo, A., 1993. Optimal Channel Networks: A framework for the study of river basin morphology. Water Resour. Res., 29, 1635-1646. 
Rigon, R., Rodriguez-Iturbe, I., Giacometti, A., Maritan, A.,Tarboton, D. and Rinaldo, R., 1996. On Hack's law. Water Resour. Res., 32, 3367-3374.

Rinaldo, A., Rodriguez-Iturbe, I., Rigon, R., Bras, R.L., IjjaszVasquez, E.J. and Marani, A., 1992. Minimum energy and fractal structures of drainage networks, Water Resour. Res., 28, 2183 2195.

Rodriguez-Iturbe, I. and Rinaldo, A., 1997. Fractal River Basins: Chance and self-organization. 208-232, Cambridge University Press, U.K.

Rodriguez-Iturbe, I., Marani, M., Rigon, R. and Rinaldo, A., 1994. Self-organised river basin landscapes: Fractal and multifractal characteristics. Water Resour. Res., 30, 3531-3539.

Seyfried, M.S. and Wilcox, B.P., 1995. Scale and the nature of spatial variability: Field examples having implications for hydrologic modelling. Water Resour. Res., 31, 173-184.
Tarboton, D.G., 1997. A new method for the determination of flow directions and contributing areas in Grid Digital Elevation Models. Water Resour. Res., 33, 309-319.

Tarboton, D.G. and Shankar, U., 1998. Invited Presentation at AGU Fall Meeting, San Francisco, December 6 to 10.

Tarboton, D.G., Bras, R.L. and Rodriguez-Iturbe, I., 1988. The fractal nature of river networks. Water Resour. Res., 24, 13171322.

Turcotte, D.L, 1997. Fractals and Chaos in Geology and Geophysics, $2^{\text {nd }}$ edition, Cambridge University Press, UK.

Veneziano, D., Moglen, G.E. and Bras, R.L., 1995. Multifractal analysis: Pitfalls of standard procedures and alternatives. Phys. Rev. E, 52, 1387-1398.

Wu, J. and Levin, S.A., 1997. A patch-based spatial modelling approach: conceptual framework and simulation scheme. Ecol. Model., 101, 325-346. 
